\title{
The Role of Gibberellins in Regulation of Nitrogen Uptake and Physiological Traits in Maize Responding to Nitrogen Availability
}

\author{
Yubin Wang ${ }^{1}$, Qingqing Yao ${ }^{1}$, Yushi Zhang ${ }^{1}{ }^{(0)}$, Yuexia Zhang ${ }^{1}$, Jiapeng Xing ${ }^{1}$, Benzhou Yang ${ }^{1}$, \\ Guohua $\mathrm{Mi}^{2}$, Zhaohu Li ${ }^{1,3}$ and Mingcai Zhang ${ }^{1, *}$ \\ 1 State Key Laboratory of Plant Physiology and Biochemistry, Engineering Research Center of Plant Growth \\ Regulator, Ministry of Education, College of Agronomy and Biotechnology, China Agricultural University, \\ Beijing 100193, China; wangyb_221@163.com (Y.W.); ksy18801291882@163.com (Q.Y.); \\ zys_0909@126.com (Y.Z.); zhangyx@126.com (Y.Z.); xjp0815@163.com (J.X.); yangbz96@163.com (B.Y.); \\ lizhaohu@cau.edu.cn (Z.L.) \\ 2 College of Resources and Environmental Science, Department of Plant Nutrition, China Agricultural \\ University, Beijing 100193, China; miguohua@cau.edu.cn \\ 3 Center for Crop Functional Genomics and Molecular Breeding, China Agricultural University, \\ Beijing 100193, China \\ * Correspondence: zmc1214@163.com
}

Received: 19 January 2020; Accepted: 3 March 2020; Published: 6 March 2020

\begin{abstract}
Modified gibberellin (GA) signaling leads to semi-dwarfism with low nitrogen (N) use efficiency (NUE) in crops. An understanding of GA-mediated N uptake is essential for the development of crops with improved NUE. The function of GA in modulating $\mathrm{N}$ uptake capacity and nitrate $\left(\mathrm{NO}_{3}{ }^{-}\right)$ transporters (NRTs) was analyzed in the GA synthesis-deficient mutant zmga3ox grown under low (LN) and sufficient (SN) $\mathrm{N}$ conditions. $\mathrm{LN}$ significantly suppressed the production of $\mathrm{GA}_{1}, \mathrm{GA}_{3}$, and $\mathrm{GA}_{4}$, and the zmga3ox plants showed more sensitivity in shoots as well as LN stress. Moreover, the higher anthocyanin accumulation and the decrease of chlorophyll content were also recorded. The net $\mathrm{NO}_{3}{ }^{-}$fluxes and ${ }^{15} \mathrm{~N}$ content were decreased in zmga3ox plants under both $\mathrm{LN}$ and $\mathrm{SN}$ conditions. Exogenous $\mathrm{GA}_{3}$ could restore the $\mathrm{NO}_{3}{ }^{-}$uptake in zmga3ox plants, but uniconazole repressed $\mathrm{NO}_{3}{ }^{-}$ uptake. Moreover, the transcript levels of $Z m N R T 2.1 / 2.2$ were downregulated in zmga3ox plants, while the $\mathrm{GA}_{3}$ application enhanced the expression level. Furthermore, the RNA-seq analyses identified several transcription factors that are involved in the GA-mediated transcriptional operation of NRTs related genes. These findings revealed that GAs influenced $\mathrm{N}$ uptake involved in the transcriptional regulation of NRTs and physiological responses in maize responding to nitrogen supply.
\end{abstract}

Keywords: maize; gibberellin; nitrogen; nitrate $\left(\mathrm{NO}_{3}{ }^{-}\right)$uptake; nitrate $\left(\mathrm{NO}_{3}{ }^{-}\right)$transporter

\section{Introduction}

Gibberellins (GAs) are phytohormones containing a tetracyclic diterpenoid structure that controls diverse aspects of plant growth and development in higher plants in response to environmental stimuli [1,2]. GA biosynthesis is catalyzed by a series of key enzymes, among which GA 20-oxidase (GA20ox) and GA 3-oxidase (GA3ox) are involved in the synthesis of bioactive GAs, and its deactivation is catalyzed by GA 2-oxidase (GA2ox) [1]. Mutations in GA biosynthesis genes (GA20ox and GA3ox) decrease the levels of endogenous GAs and lead to dwarfism, whereas exogenous GA treatment can restore normal growth [3,4]. DELLA proteins (DELLAs) are the major component in the GA signaling pathway. GAs promote plant growth by stimulating the degradation of the growth-repressing DELLAs [5]. Most importantly, dwarfism in rice and wheat cultivars was selected for enhancing global 
food production during the "green revolution". These dwarfing characteristics were modulated by changing the GA metabolic and signaling pathways [6]. For instance, the mutant wheats Rht-B1b and Rht-D1b, encoding DELLAs, were resistant to GA-induced loss of semi-dominant GA-insensitive dwarfism [7], while the rice semidwarf-1 $(s d-1)$ gene was defective in GA 20-oxidase, leading to a decline in the bioactive GA abundance [8,9], which increased the accumulation of the DELLA protein SLR1 (Slender Rice1) [10].

Previous studies have demonstrated that GA plays essential roles in many aspects of the adaptation of plant growth during the nutrient-deficiency stresses. In Arabidopsis, phosphate (Pi) starvation enhanced the accumulation of DELLAs in the roots, and DELLA-mediated signaling contributed to the anthocyanin accumulation [11]. Moreover, low Pi induced the expression of high-affinity Pi transporters, which are impaired in the tomato GA biosynthetic mutant gib3 [12]. In addition, low potassium $(\mathrm{K})$ promoted the accumulation of DELLA protein in the root, and the expression of high-affinity potassium transporter 5 (AtHAK5) was repressed in mutant gai-1, which reduced $\mathrm{K}$ uptake and decreased $\mathrm{K}$ deprivation tolerance [13]. Li et al. reported that a rice transcription factor (growth-regulation factor; OsGRF4) positively regulated $\mathrm{N}$ use, and an antagonistic relationship between OsGRF4 and DELLA protein OsSLR1 was maintained, which coordinated the plant growth and $\mathrm{N}$ metabolism [10]. DELLAs interact with anthocyanin pigmentation 1 (PAP1) to upregulate the expression of anthocyanin biosynthetic related genes under $\mathrm{N}$ deficiency [14]. However, the mechanism of $\mathrm{N}$ uptake and its allocation by GAs in crops subjected to different $\mathrm{N}$ level conditions is yet to be known.

It was reported that exogenous $\mathrm{GA}_{3}$ enhanced $\mathrm{N}$ use efficiency (NUE) in mustard, tomato, and cucumber [15-17]. In contrast, a decrease in $\mathrm{N}$ uptake was observed in mutant $s d 1$ and $R h t$ alleles [10]. Thus, $s d 1$ reduced the rate of ammonium $\left(\mathrm{NH}_{4}{ }^{+}\right)$uptake and modulated $\mathrm{N}$-responsive regulation in rice. A similar phenomenon was observed during the nitrate $\left(\mathrm{NO}_{3}{ }^{-}\right)$uptake in mutant wheat $R h t-B 1 b$ plants [10]. Consequently, the dwarfism was the reason for more $\mathrm{N}$ fertilizer to be applied for higher yield during the "green revolution", which resulted in lower NUE in crop production $[6,18]$. Plant NUE is inherently complex, and it is important to understand the function and regulation of the key components involved in $\mathrm{N}$ uptake, translocation, assimilation, and remobilization [19]. In consequence, GA signaling regulates the N uptake in crops, and it is necessary to enhance NUE for the development of new GA-insensitive dwarfing varieties [20]. Accordingly, it is essential to explore the physiological and molecular aspects of GAs in regulating $\mathrm{N}$ uptake and allocation in plants.

Maize is an important crop worldwide that is cultivated in aerobic soils. It requires a high amount of N fertilizer [21], and NUE has been the major limitation in the past 50 years [22]. It is essential to verify the physiological and molecular mechanisms in maize for breeding the $\mathrm{N}$-efficient cultivars [23]. In general, nitrate is the major form of $\mathrm{N}$ source in aerobic soils [24], and $\mathrm{NO}_{3}{ }^{-}$transporters (NRTs) assist in $\mathrm{NO}_{3}{ }^{-}$uptake and its utilization throughout the lifecycle of plants [25,26]. Moreover, plant $\mathrm{NO}_{3}{ }^{-}$uptake generally involves low-affinity transport systems (LATS) and high-affinity transport systems (HATS). LATS and HATS have been associated with the NPF/NRT1 and NRT2 families (including NRT2.1 and NRT2.2), respectively [25]. Moreover, the expression of primary NPF (nitrate transporter1/peptide transporter family) genes, NPF6.3 and NRT2.1, can be regulated by auxin, ethylene, and cytokinin, which influence $\mathrm{N}$ uptake [27]. Low $\mathrm{N}$ reduces GA synthesis and represses plant growth. Exogenous $\mathrm{GA}_{3}$ can restore plant growth in maize even when subjected to low $\mathrm{N}$ supply [28]. Although modulating the action of GA can alter $\mathrm{N}$ uptake and allocation, little is known about how GA regulates $\mathrm{N}$ uptake in crops.

The aim of the present research is to investigate the role of GAs in the regulation of physiological responses to $\mathrm{N}$ supply in maize. The GA synthesis deficient mutant zmga3ox was constructed and combined with exogenous $\mathrm{GA}_{3}$ and uniconazole (an inhibitor of GA biosynthesis, Ucz) for analyzing $\mathrm{N}$ uptake under $\mathrm{LN}$ and SN conditions. Moreover, GA-mediated $\mathrm{NO}_{3}{ }^{-}$uptake was evaluated by using the non-invasive micro-test (NMT) and the ${ }^{15} \mathrm{~N}$ labeling technique. Furthermore, an RNA-seq assay was conducted to investigate the role of GAs in modulating $\mathrm{N}$ uptake at the transcript profiles. 
Thereby, the present study demonstrates the role of the GA in regulating the physiological responses in maize in correspondence to $\mathrm{N}$ supply.

\section{Results}

\subsection{Characterization of zmga3ox Mutant in Maize}

The GA3ox enzymes participate in the synthesis of bioactive GAs and catalyze the conversion of $\mathrm{GA}_{9}$ to bioactive $\mathrm{GA}_{4}$ and $\mathrm{GA}_{20}$ to $\mathrm{GA}_{1}$ and $\mathrm{GA}_{3}$ (Figure 1a). In order to verify the role of GAs in response to $\mathrm{N}$ supply in maize, the knockout mutants were generated using a type II CRISPR-Cas9 system [29]. A knockout mutant named zmga3ox was obtained, which conferred a 34-bp deletion causing a frameshift in $Z m G A 30 x$ (Figure $1 \mathrm{~b}-\mathrm{d}$ ). Compared to the wild-type plant, the expression level of ZmGA3ox was hardly detected in the shoots and roots of zmga3ox plant (Figure S1). Meanwhile, the zmga3ox plant displayed growth inhibition, and exogenous $\mathrm{GA}_{3}$ could restore normal growth (Figure 1e). The concentrations of $\mathrm{GA}_{1}, \mathrm{GA}_{3}$, and $\mathrm{GA}_{4}$ in zmga3ox plant were significantly lower than those in wild-type plants (Figure 1f). Also, the zmga3ox plant had greater levels of $\mathrm{GA}_{9}$ and $\mathrm{GA}_{20}$ compared to the wild-type (Figure $1 \mathrm{~g}$ ). These results suggest that zmga3ox is an endogenous GA-defective mutant.

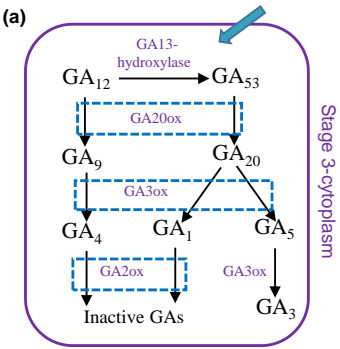

(e)

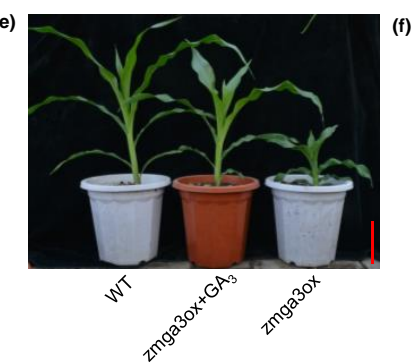

(b)

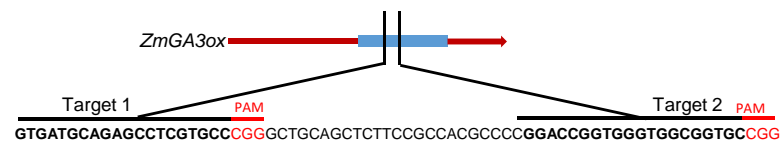

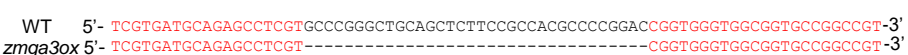

(d) zmga3ox QSLVGGWRCRPCRAPSSSTWATSSTSSPTAGSTACTTAPSTGTSTGSRSATSSARRR
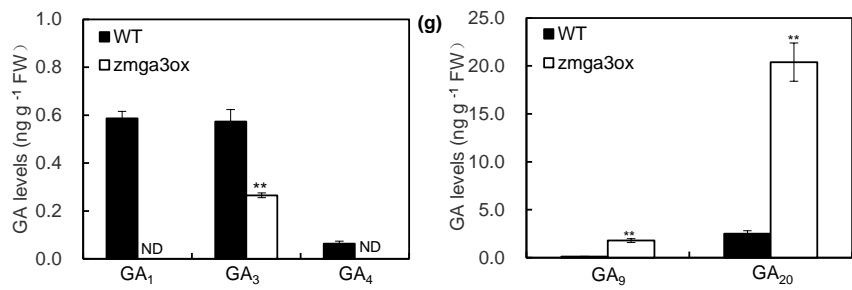

Figure 1. The $Z m G A 3 o x$ knockout mutant characterization and phenotype analysis under sufficient nitrogen (SN) condition. (a) Schematic representations of the GAs biosynthesis pathway; (b) targeted mutagenesis of ZmGA3ox via CRISPR-Cas9; protospacer adjacent motif (PAM) sequences labelled in red; (c) sequence information of the gene-editing region in wild-type and zmga3ox plants; (d) alignment of the amino acid sequences of $Z m G A 3 o x$ and zmga3ox. Only the sequences flanking the mutations were shown, and the frameshifted sequences in zmga3ox highlighted in red. (e) The phenotype of the zmga3ox and $\mathrm{GA}_{3}$-treated zmga3ox seedling. Bar $=20 \mathrm{~cm}$. (f) The contents of $\mathrm{GA}_{1}, \mathrm{GA}_{3}$, and $\mathrm{GA}_{4}$ in shoots of zmga3ox and wild-type seedlings. ND: not detected. (g) The contents of $\mathrm{GA}_{9}$ and $\mathrm{GA}_{20}$ in shoots of zmga3ox and wild-type seedlings. Values were the means $\pm \mathrm{SD}(n=3)$. The asterisks indicated significant difference between wild-type and zmga3ox plants, as evaluated by Student's $t$-tests ** $p<0.01$.

\subsection{GAs Altered the Anthocyanin Accumulation and Chlorophyll Content in Leaves in Response to $\mathrm{NO}_{3}{ }^{-}$Supply}

The anthocyanin and chlorophyll contents were determined in wild-type and zmga3ox seedlings by growing in $\mathrm{LN}$ and $\mathrm{SN}$ solutions with or without $\mathrm{GA}_{3}$ and $\mathrm{Ucz}$. The zmga3ox plants were more sensitive to LN supply than the wild-type plant, and also the zmga3ox leaves were more purple. As 
expected, the $\mathrm{GA}_{3}$-treated leaves were less purple, but Ucz strengthened such effect. Moreover, the application of $\mathrm{GA}_{3}$ and $\mathrm{Ucz}$ had no effect on the anthocyanin accumulation under the SN condition (Figure 2a). LN significantly enhanced the accumulation of the anthocyanin in zmga3ox leaves, and the anthocyanin content was increased by 3 -fold under the LN condition (Figure 2b). In addition, the chlorophyll content was decreased in zmga3ox leaves compared to the wild-type leaves under $\mathrm{LN}$ condition, and exogenous $\mathrm{GA}_{3}$ increased the chlorophyll content in both wild-type and zmga3ox leaves; however, Ucz treatment slightly decreased the chlorophyll content in both wild-type and $z m g a 3 o x$ leaves (Figure 2c). $\mathrm{GA}_{3}$ treatment declined the chlorophyll content in zmga3ox leaves under SN condition, while Ucz treatment enhanced the chlorophyll content. In addition, the photosynthetic rate, leaf areas, and $\mathrm{O}_{2}{ }^{-}$production rate were also measured in the wild-type and zmga3ox leaves treated with or without $\mathrm{GA}_{3}$ application. The zmga3ox leaves showed higher the photosynthetic rate than the wild-type leaves, while the photosynthetic rate was decreased by $\mathrm{GA}_{3}$ treatment (Figure S2a). Moreover, the leaf areas of the zmga3ox plants were significantly less than those of the wild-type plants (Figure S2b). Furthermore, the $\mathrm{O}_{2}{ }^{-}$production rate in zmga3ox leaves showed slightly lower than that in wild-type leaves (Figure S2c).

(a)
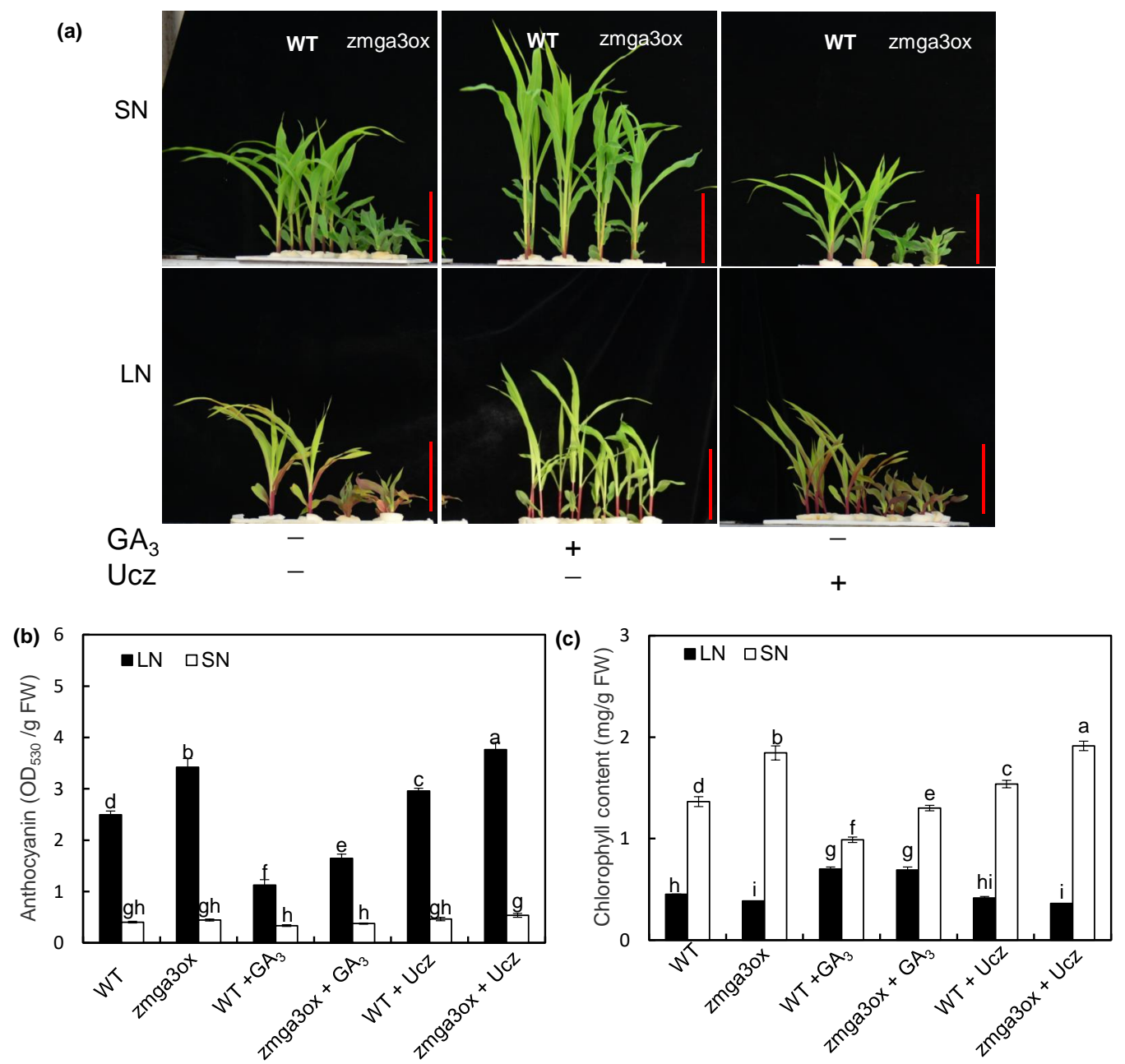

Figure 2. The anthocyanin accumulation and chlorophyll content in zmga3ox leaves under LN or SN condition. (a) Appearance of the $\mathrm{GA}_{3}$ or Ucz-treated wild-type and zmga3ox leaves at $7 \mathrm{~d}$ after LN or $\mathrm{SN}$ treatment. Bar $=10 \mathrm{~cm}$. (b) The content of anthocyanin in zmga3ox shoots treated with $\mathrm{GA}_{3}$ or Ucz at $7 \mathrm{~d}$ after $\mathrm{LN}$ or SN treatment. Values were the means $\pm \mathrm{SD}(n=3)$. (c) The content of chlorophyll in $z m g a 30 x$ shoots treated with $\mathrm{GA}_{3}$ or $\mathrm{Ucz}$ at $7 \mathrm{~d}$ after $\mathrm{LN}$ or $\mathrm{SN}$ treatment. Values were the means $\pm \mathrm{SD}$ $(n=3)$. Different letters indicated significant difference calculated by Fisher's LSD $(p<0.05)$. 


\subsection{Supply of $\mathrm{NO}_{3}{ }^{-}$Modulated the Transcript Expression of $\mathrm{GA}$ Biosynthesis- and Metabolism-Related Genes}

In order to understand the role of GAs in maize corresponding to $\mathrm{NO}_{3}{ }^{-}$supply, the content of $\mathrm{GA}_{1}, \mathrm{GA}_{3}$, and $\mathrm{GA}_{4}$ was determined by using the HPLC-MS/MS method. LN significantly decreased the content of $\mathrm{GA}_{1}, \mathrm{GA}_{3}$, and $\mathrm{GA}_{4}$ in roots as compared to $\mathrm{SN}$ (Figure $3 \mathrm{a}$ ). The $\mathrm{GA}_{1}$ content could not be detected in the roots under the LN condition, while the $\mathrm{GA}_{3}$ and $\mathrm{GA}_{4}$ levels were lower under $\mathrm{LN}$ condition than those under the $\mathrm{SN}$ condition. The expression levels of ent-kaurene synthase genes ZmKS2 and ZmKS4 in GA biosynthesis pathway were significantly downregulated by LN in comparison to SN (Figure 3b). Similarly, LN significantly decreased the expression levels of ZmGA20ox1 and $Z m G A 20 o x 4$ (Figure 3c). LN enhanced the expression levels of catabolic genes ZmGA2ox1, ZmGA2ox5,

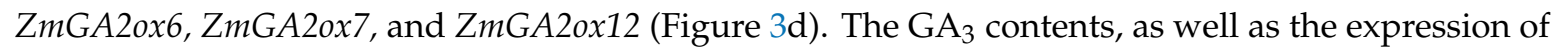
genes encoding enzymes of GA metabolism, were also determined in the zmga3ox mutant. As shown in Figure S3, the levels of $\mathrm{GA}_{3}$ were less under $\mathrm{LN}$ condition than those under the $\mathrm{SN}$ condition (Figure S3a). LN significantly down-regulated the expression levels of GA biosynthetic enzyme genes ZmKS2, ZmKS4, ZmGA20ox1, and ZmGA20ox4 (Figure S3b,c). Inversely, LN enhanced the expression levels of catabolic enzyme genes ZmGA2ox1, ZmGA2ox5, ZmGA2ox6, ZmGA2ox7, and ZmGA2ox12 (Figure S3d). The results indicated that $\mathrm{LN}$ caused a reduction in the bioactive $G A_{S}$ levels in roots by regulating the transcripts encoding GA 20-oxidases and GA 2-oxidases.
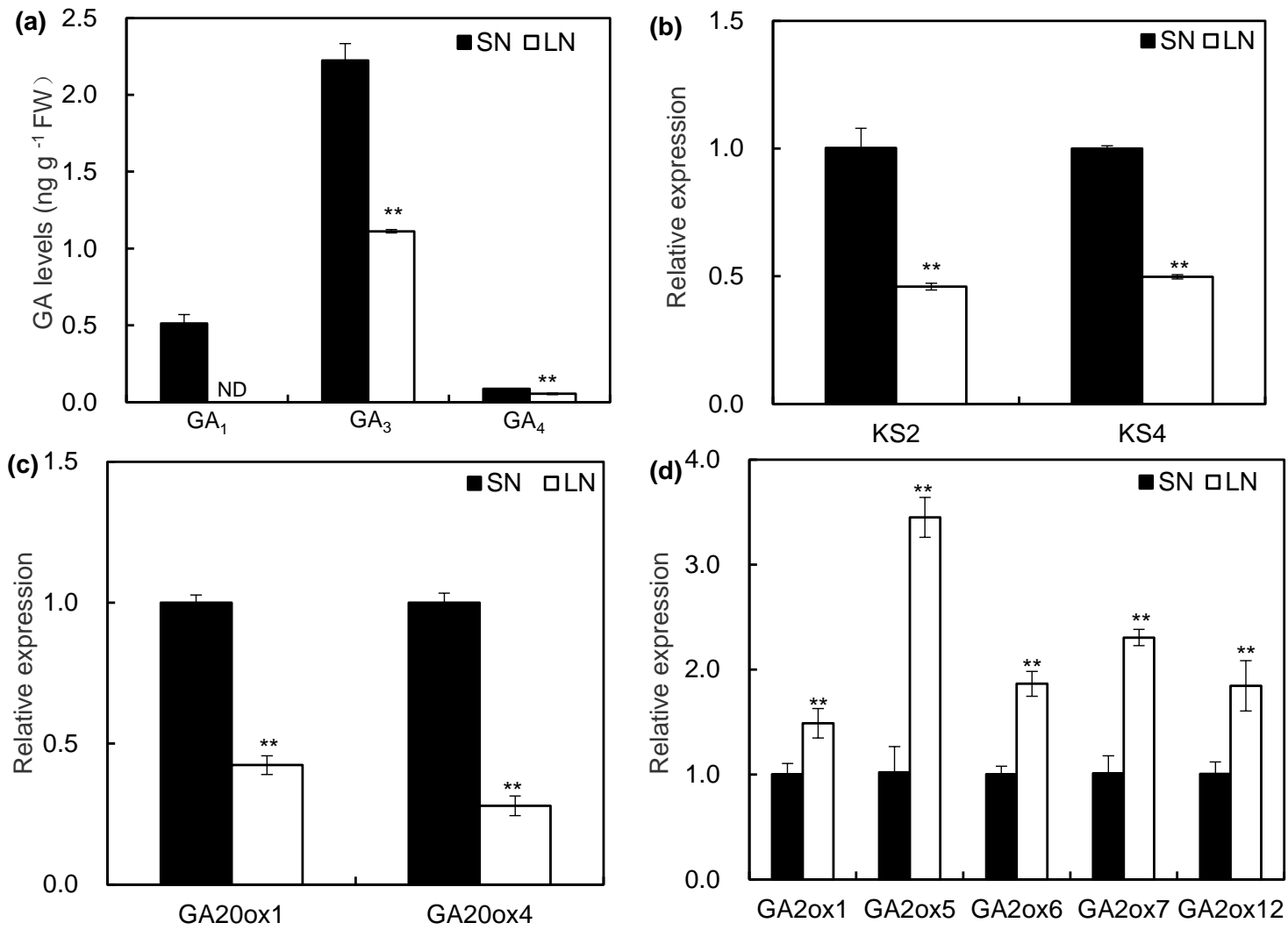

Figure 3. The GA contents and the expression levels of GA biosynthesis- and catabolic related genes in maize seedlings responded to $\mathrm{LN}$ and $\mathrm{SN}$. (a) The contents of $\mathrm{GA}_{1}, \mathrm{GA}_{3}$, and $\mathrm{GA}_{4}$ in the wild-type roots at $5 \mathrm{~d}$ after LN and SN. ND: not detected. (b-d) The transcriptional levels of ent-kaurene synthases (b), GA 20-oxidases (c), and GA 2-oxidase (d) genes in the wild-type roots at $3 \mathrm{~d}$ after LN and SN treatment. $(\mathbf{a}-\mathbf{d})$ Values were the means $\pm \mathrm{SD}(n=3)$. The asterisks indicated significant difference compared with the control as evaluated by Student's $t$-tests ${ }^{* *} p<0.01$. 


\subsection{GAs Involved in Manipulating the $\mathrm{NO}_{3}{ }^{-}$Uptake}

In order to characterize the function of GAs in regulating the $\mathrm{N}$ uptake, the net $\mathrm{NO}_{3}{ }^{-}$fluxes were measured by using the NMT technique in wild-type and zmga3ox roots. As shown in Figure 4a, the uptake of $\mathrm{NO}_{3}{ }^{-}$was evidently decreased in zmga3ox root compared to wild-type under SN and LN conditions. The mean $\mathrm{NO}_{3}{ }^{-}$fluxes were lower by $266 \%$ and $23.8 \%$ in zmga3ox root than wild-type under SN and LN conditions, respectively (Figure $4 \mathrm{~b}$ ). Moreover, $\mathrm{LN}$ repressed the ${ }^{15} \mathrm{~N}$ content in both wild-type and zmga3ox roots. The amount of ${ }^{15} \mathrm{~N}$ in zmga3ox roots was less than that in the wild-type roots under LN and SN conditions (Figure 4c). LN reduced the $\mathrm{N}$ content in root and shoot, and the zmga3ox plants had less $\mathrm{N}$ content than the wild-type plants under LN and SN conditions (Figure 4d). The $\mathrm{N}$ contents in zmga3ox root and shoot were less by $89.5 \%$ and $77.2 \%$ than those in wild-type under $\mathrm{LN}$ condition, and similar results were recorded for $\mathrm{SN}$.
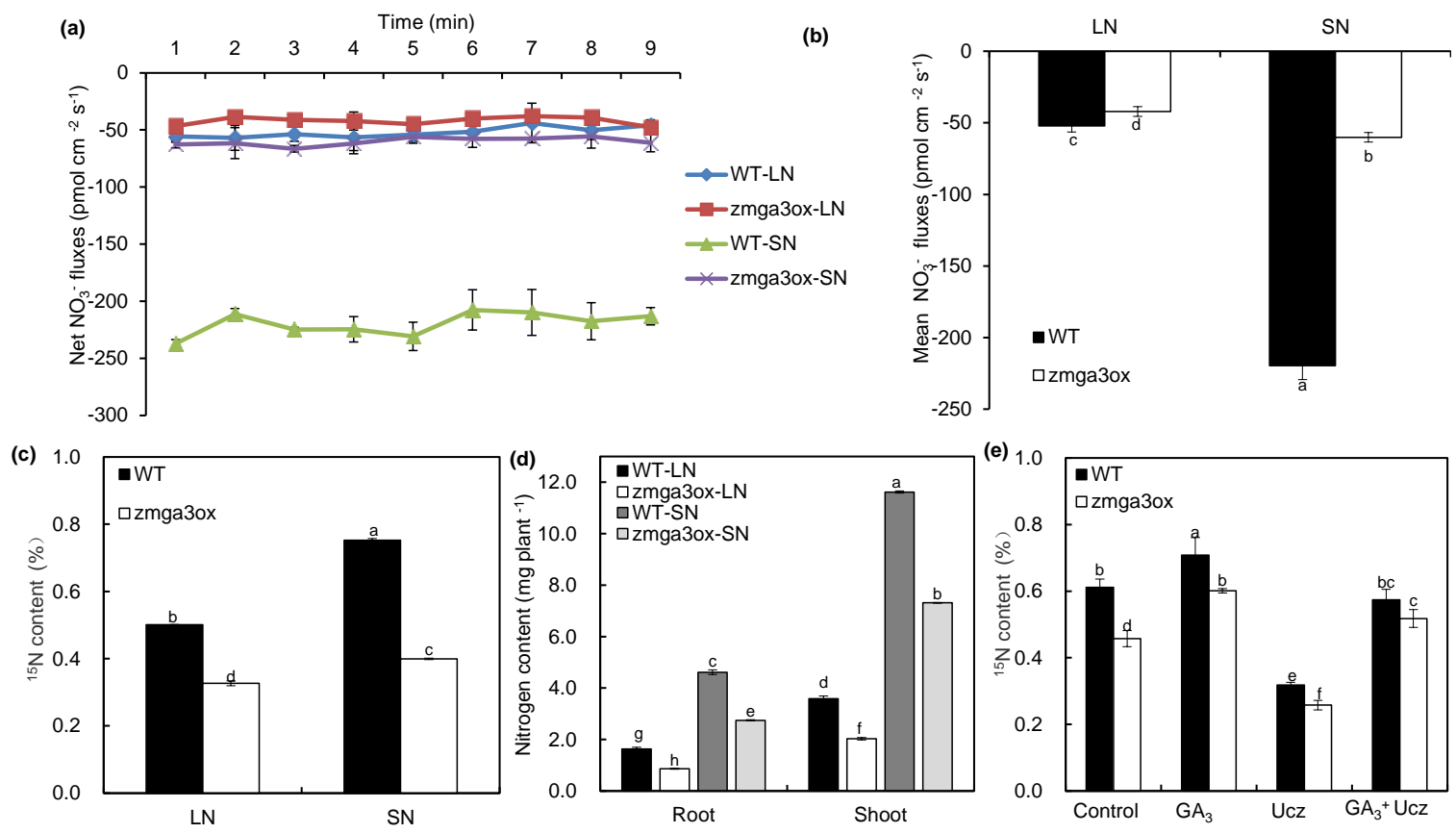

Figure 4. Nitrate uptake and allocation in zmga3ox plants under LN and SN conditions. (a-b) The net $\mathrm{NO}_{3}{ }^{-}$flux (a), and the mean $\mathrm{NO}_{3}{ }^{-}$flux (b) along the maturation zone of wild-type and zmga3ox primary root. Values were the means $\pm \mathrm{SD}(n=7)$. (c) The ${ }^{15} \mathrm{~N}$ content after $10 \mathrm{~min}{ }^{15} \mathrm{~N}$ tracing assay in wild-type and zmga3ox plants; (d) total $\mathrm{N}$ content per plant in shoots and roots of wild-type and zmga3ox plants; (e) the ${ }^{15} \mathrm{~N}$ content in wild-type and zmga3ox seedlings treated with $\mathrm{GA}_{3}$ and/or uniconazole (Ucz). (c-e) Values were the means $\pm \mathrm{SD}(n=3)$. Different letters indicated significant difference calculated by Fisher's LSD $(p<0.05)$.

In order to further investigate the role of GAs in the regulation of $\mathrm{N}$ uptake, exogenous $\mathrm{GA}_{3}$ and Ucz were applied. $\mathrm{GA}_{3}$ treatment could increase the amount of ${ }^{15} \mathrm{~N}$ in wild-type and zmga3ox plants (Figure 4e). On the other hand, Ucz treatment significantly decreased the amount of ${ }^{15} \mathrm{~N}$ in wild-type and zmga3ox plants. The combined $\mathrm{GA}_{3}$ and Ucz treatments restored the amount of ${ }^{15} \mathrm{~N}$ in Ucz-treated plants while decreased that in $\mathrm{GA}_{3}$-treated plants.

To clarify the effects of GA on $\mathrm{N}$ uptake whether derived from differences in plant growth and nutritional status, the dry weight and total $\mathrm{N}$ content in the wild-type and zmga3ox plants were analyzed under LN or SN condition. Although the dry weight of shoots and roots were lower in zmga3ox plants than the wild-type plants under both LN and SN conditions, the inhibition rate of LN to SN in dry biomass of shoot or root presented no significant difference between wild-type and zmga3ox plants (Figure S4a-d). Similarly, the zmga3ox plants had lower total N content in shoots and 
roots compared to the wild-type plants. However, the inhibition rate of $\mathrm{LN}$ to $\mathrm{SN}$ in total $\mathrm{N}$ content of shoot or root showed significant difference between wild-type and zmga3ox plants (Figure S4e-h).

\subsection{GAs Modulated the Transcript Expression of $\mathrm{NO}_{3}{ }^{-}$Uptake-Related Genes}

In order to ascertain the mechanism of GA affecting the $\mathrm{N}$ uptake, the expression levels of $\mathrm{NO}_{3}{ }^{-}$ uptake-related genes were detected in wild-type and zmga3ox roots subjected to SN and LN. As shown in Figure 5, the expression levels of ZmNRT2.1 and ZmNRT2.2 in zmga3ox roots were lower than those of wild-type roots under LN and SN conditions (Figure 5a,b). The transcript expression of ZmNRTs was also detected in the $\mathrm{GA}_{3}$-treated wild-type and zmga3ox plants. $\mathrm{GA}_{3}$ treatment could significantly enhance the expression levels of ZmNRT2.1 and ZmNRT2.2 in wild-type and zmga3ox plants under LN and SN conditions. Meanwhile, LN downregulated the expression of ZmNPF6.3b in wild-type and zmga3ox roots, while the expression level of ZmNPF6.3a showed no significant difference between wild-type and zmga3ox roots (Figure 5c). The zmga3ox root had higher expression levels of ZmNPF6.3b than the wild-type root under the LN condition (Figure $5 d$ ). In addition, the expression levels of ZmNPF6.3a and ZmNPF6.3b showed no significant difference in $\mathrm{GA}_{3}$-treated both wild-type and zmga3ox plants under both LN and SN conditions.

(a)

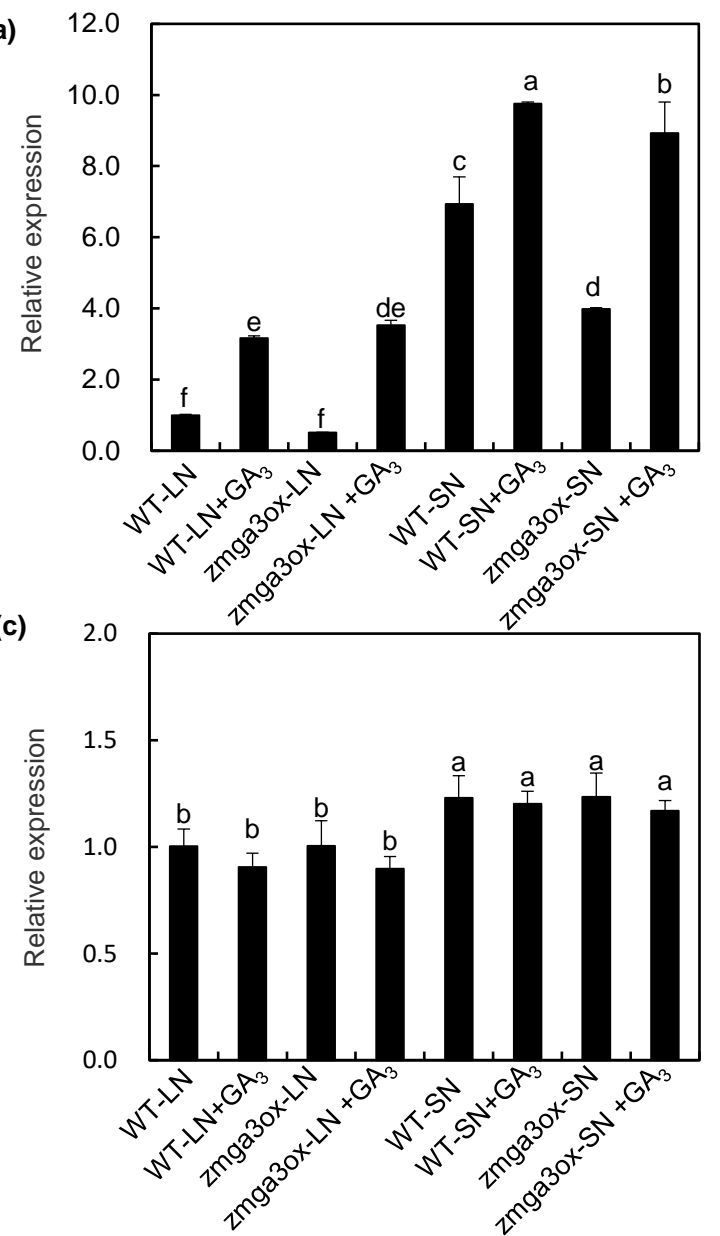

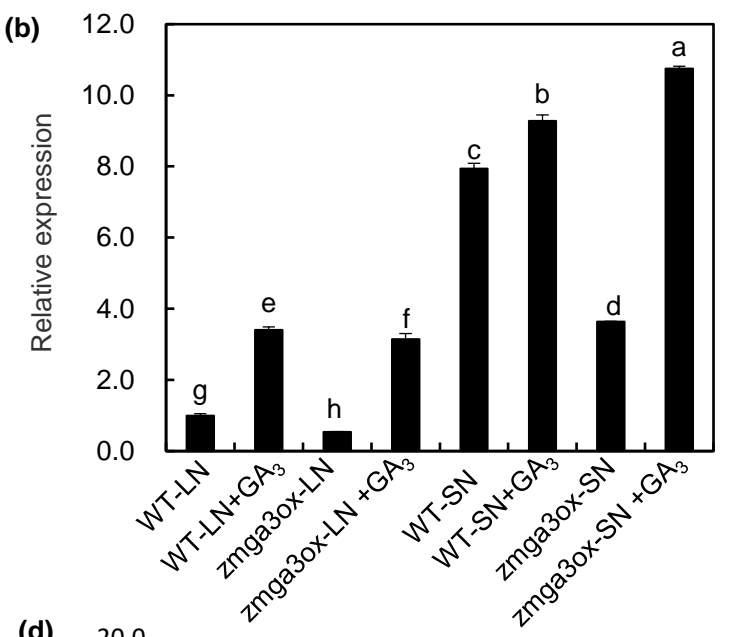

(d)

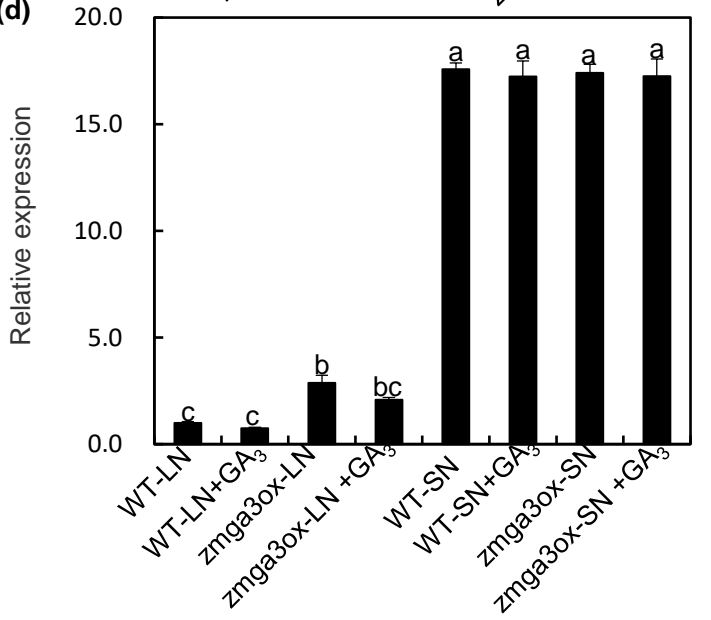

Figure 5. Effects of exogenous $\mathrm{GA}_{3}$ on the expression levels of ZmNRT2.1 (a), ZmNRT2.2 (b), ZmNPF6.3a (c), and ZmNPF6.3b (d) in wild-type and zmga3ox roots under LN and SN conditions. The roots were harvested at $72 \mathrm{~h}$ after $\mathrm{GA}_{3}$ treatment under $\mathrm{LN}$ and SN conditions. Values were the means $\pm \mathrm{SD}$ $(n=3)$. Different letters indicated significant difference calculated by Fishe's LSD $(p<0.05)$. 
2.6. RNA-Sequencing Revealed Differentially Expressed Genes (DEGs) in the Wild-Type and zmga3ox Plants in Response to $\mathrm{NO}_{3}{ }^{-}$Supply

In order to gain molecular insights into the roles of GAs in the regulation of $N$ uptake, the RNA-seq assay was conducted. This helped identify the differentially expressed genes (DEGs) in the wild-type and zmga3ox roots at 12,60 , and $108 \mathrm{~h}$ after the $\mathrm{LN}$ or SN treatment. The statistics of the clean reads in the RNA-seq are shown in Table S1. A total of 3054 DEGs were identified after filtering with a threshold of $\left|\log _{2} \mathrm{FC}\right| \geq 1$ under the FDR (false discovery rate) $<0.05$ (Table S2). The Venn diagrams showed the number of DEGs in different samples. A greater number of DEGs were downregulated compared to the number of upregulated DEGs under both the LN and SN conditions. Furthermore, a greater number of DEGs were identified under the SN treatment compared to the $\mathrm{LN}$ treatment. The samples collected after $108 \mathrm{~h}$ showed the maximum number of DEGs under the LN as well as SN conditions (Figure 6a). Besides, the heat map suggested that the level of change (fold change) in the expression of these DEGs was higher after 60 and $108 \mathrm{~h}$ than that after the $12 \mathrm{~h}$ treatment (Figure S5).

(a)

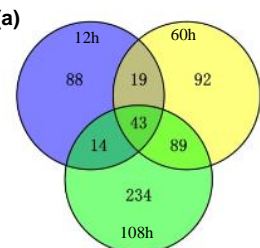

LN-Up regulated

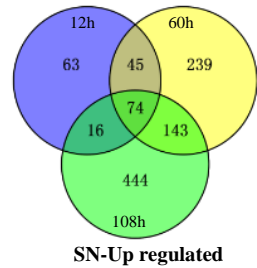

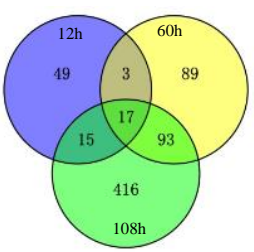

LN-Down-regulated

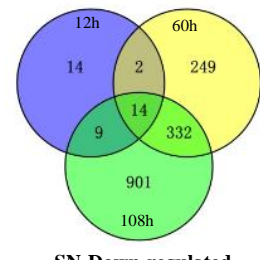

SN-Down-regulated

(b)

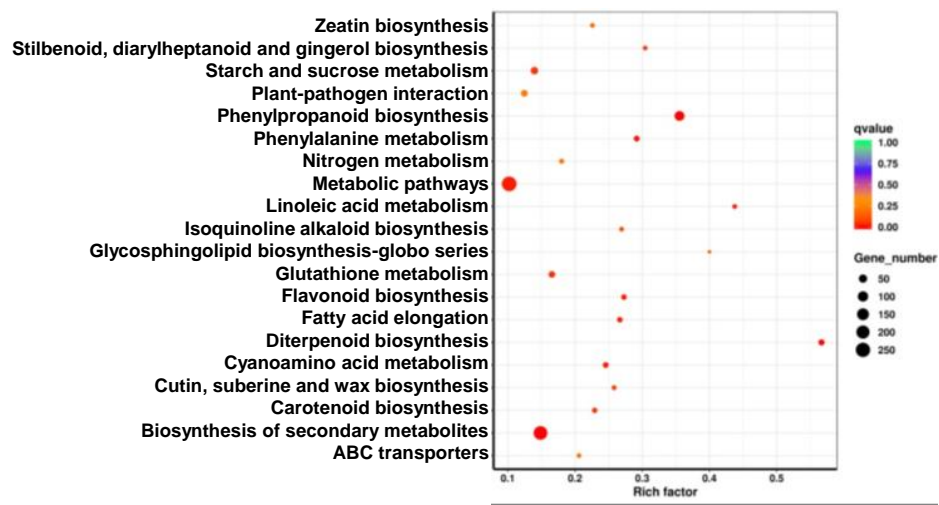

(d)

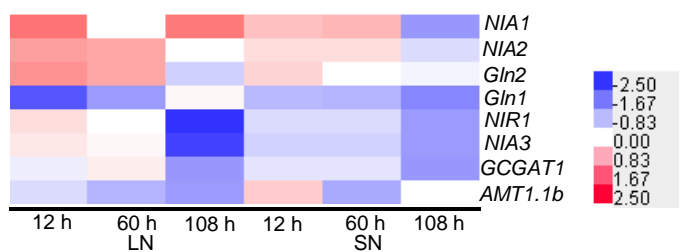

(c)

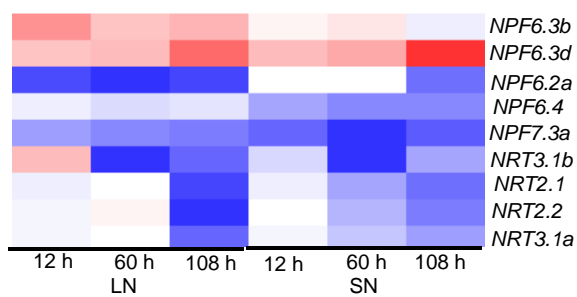

Figure 6. The DEGs involved in $\mathrm{NO}_{3}{ }^{-}$uptake and metabolism. (a) Venn diagrams showed the upand downregulated significantly differentially expressed genes (DEGs) identified by RNA-seq in the wild-type and zmga3ox roots at 12,60, and $108 \mathrm{~h}$ after LN and SN treatments, respectively; (b) list of the top 20 significant enriched KEGG pathway of significantly regulated DEGs. (c,d) Heatmap showed the DEGs involved in $\mathrm{NO}_{3}{ }^{-}$uptake and transport (c), $\mathrm{N}$ assimilation and $\mathrm{NH}_{4}{ }^{+}$uptake (d). Genes annotated by MaizeGDB gene model were shown with gene name. Different expression levels were shown as $\log _{2} \mathrm{FC}$, blue for downregulation and red for upregulation, as shown in color bar.

The GO (Gene Ontology) database and KEGG (Kyoto Encyclopedia of Genes and Genomes) enrichment analysis were employed to investigate the function of the 3054 DEGs and to understand the regulatory pathways that respond to the $\mathrm{N}$ supply in the zmga3ox mutant (Tables S3 and S4). The biosynthesis of phenylpropanoid and secondary metabolites was highly enriched in these DEGs (Figure 6b and Table S4). Moreover, the KEGG analysis revealed that the most significantly enriched pathway was the $\mathrm{N}$-metabolism pathway, and this included the genes related to the $\mathrm{NO}_{3}{ }^{-}$transporter, $\mathrm{NO}_{3}{ }^{-}$reductase, and glutamate synthase (Figure $6 \mathrm{~b}$ and Table S4). Thus, three NPF/NRT1 genes were downregulated, including ZmNPF6.2a, ZmNPF6.4, and ZmNPF7.3a. On the contrary, the expression of 
ZmNPF6.3b was upregulated under LN condition, and the expression of ZmNPF6.3d was upregulated under both $\mathrm{LN}$ as well as SN conditions (Figure $6 c$ and Table S5). Also, two ZmNRT2s genes were identified and these ZmNRT2.1 and ZmNRT2.2 genes were downregulated. Moreover, the ZmNRT3.1a and $Z m N R T 3.1 b$ genes also showed downregulated expression (Figure $6 \mathrm{c}$ and Table S5). The other eight important DEGs were identified as the $\mathrm{N}$ assimilation-related genes, including ZmNIA1, ZmNIA2, ZmGln2, ZmGln1, ZmNIR1, ZmNIA3, ZmGOGAT1 and the $\mathrm{NH}_{4}{ }^{+}$transporter gene ZmAMT1.1b (Figure 6d and Table S5); most of these important DEGs were downregulated in the zmga3ox plants.

In order to further investigate the role of GAs in the transcript regulation of $\mathrm{N}$ uptake and assimilation, the transcripts of the important DEGs involved in this process were evaluated by the RT-qPCR analysis. As expected, all the selected genes had similar expression patterns in the RNA-seq results (Figure 7 and Table S5). LN decreased the expression levels of ZmNRT2.1 and ZmNRT2.2 compared to SN at 60 and $108 \mathrm{~h}$ after treatment, and the expression levels of ZmNRT2.1 and ZmNRT2.2 in the zmga3ox plant were lower than those in the wild-type plant, except for $12 \mathrm{~h}$ after LN treatment (Figure 7a,b). Similar trends were observed in the expression of ZmNPF6.4 under SN condition (Figure 7c). However, the expression levels of ZmNPF7.3a were upregulated by LN compared to that by SN, and the zmga3ox plant showed lower expression levels of ZmNPF7.3a than the wild-type plant after 60 and $108 \mathrm{~h}$ of the LN or SN treatments (Figure 7d). Inversely, LN significantly downregulated the expression levels of $Z m N P F 6.3 b$ compared to SN, and the expression levels of ZmNPF6.3b in the $z m g a 30 x$ plant were higher than those in the wild-type plant after 60 and $108 \mathrm{~h}$ of the LN treatment (Figure 7e). Meanwhile, the LN treatment downregulated the expression levels of ZmGOGAT1 and ZmNIR1 compared to the SN treatment, and the expression levels of ZmGOGAT1 and ZmNIR1 in the zmga3ox plant were lower than those in the wild-type plant at 60 and $108 \mathrm{~h}$ after the LN and SN treatments (Figure S6a,b). Similarly, the expression of ZmGln1 and ZmNIA1 was repressed at 60 and $108 \mathrm{~h}$ after the LN treatment, while the zmga3ox plant showed downregulated trend of $Z m G \ln 1$ and ZmNIA1 than the wild-type plant (Figure S6c,d). Correspondingly, LN reduced the activities of nitrate reductase (NR) and glutamine synthase (GS); the activities of NR and GS in the zmga3ox plant were significantly lower than those in the wild-type plant (Figure S7). 

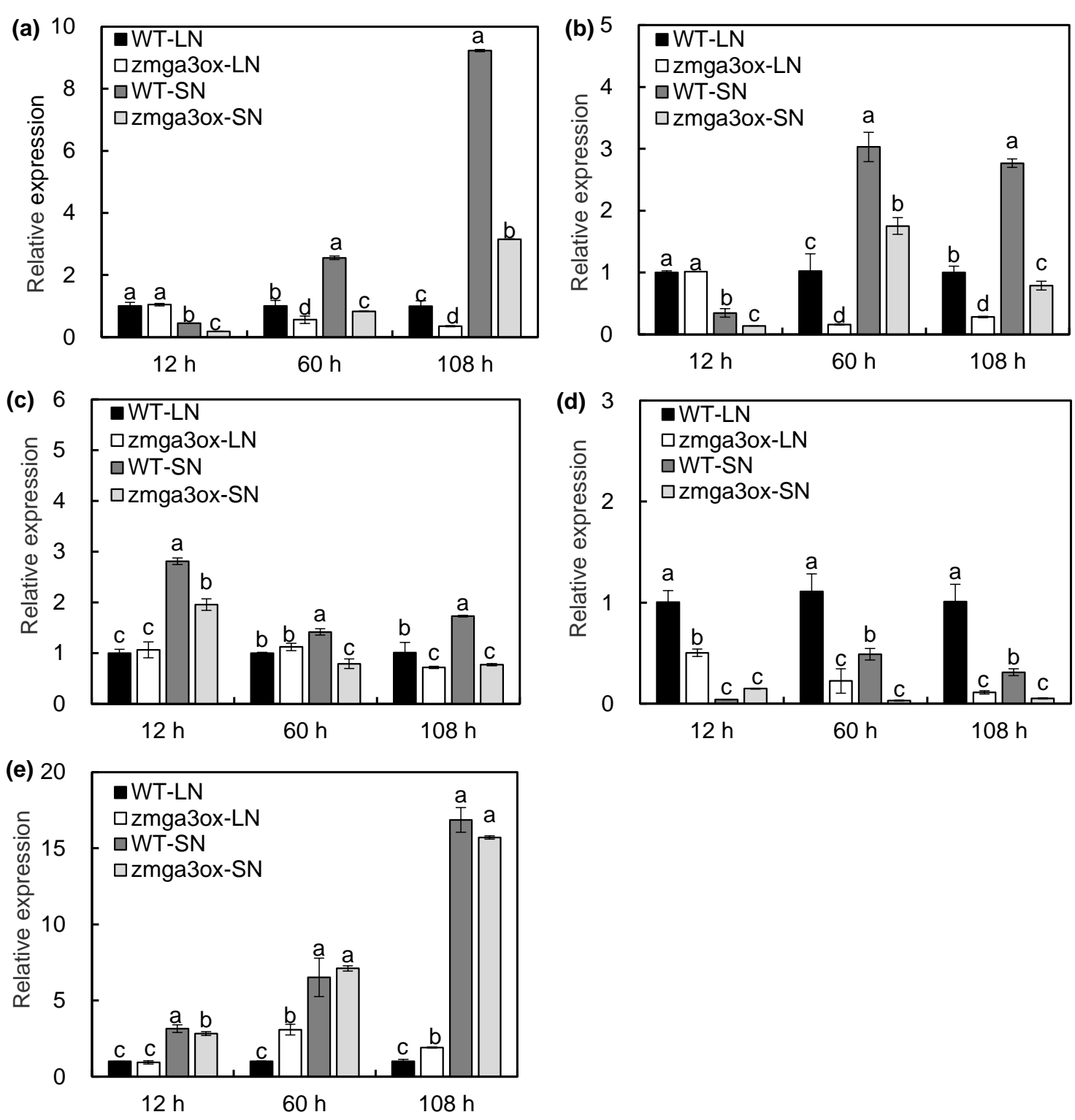

Figure 7. The expression levels of ZmNRT2.1 (a), ZmNRT2.2 (b), ZmNPF6.4 (c), ZmNPF7.3a (d), and ZmNPF6.3b (e) in wild-type and zmga3ox roots under LN and SN conditions. Roots were harvested at 12,60 , and $108 \mathrm{~h}$ after LN and SN treatments. Values were the means \pm SD $(n=3)$. Different letters indicated significant difference between the wild-type and zmga3ox plants at the same time point calculated by Fisher's LSD $(p<0.05)$.

\subsection{Transcription Factors Involved in GA-Mediated $\mathrm{NO}_{3}{ }^{-}$Uptake}

The transcriptional control of $\mathrm{NO}_{3}{ }^{-}$uptake is well-documented over the past decade, in which transcription factors (TFs) play an important regulatory role [30]. The RNA-seq analysis revealed that a total of 287 important DEGs were identified as TFs (Table S6). To predict the targets of transcriptional regulation, the TF-binding sites were predicted from the putative promoter sequences $(2 \mathrm{~kb}$ upstream from the transcriptional start site) of the nine identified nitrate transporter genes. As shown in Figure 8a and Table S7, 25 TFs were predicted to be involved in the regulation of nitrate transporter genes. The number of binding sites of the $M Y B, W R K Y$, and ERF families was the greatest, followed by the $L B D, T C P$, and $b Z I P$ family TFs. 
(a)

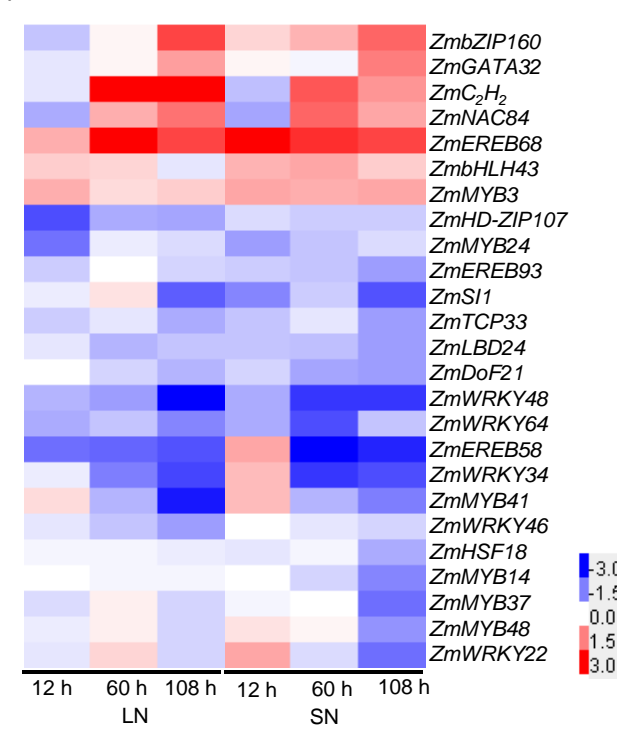

(b)

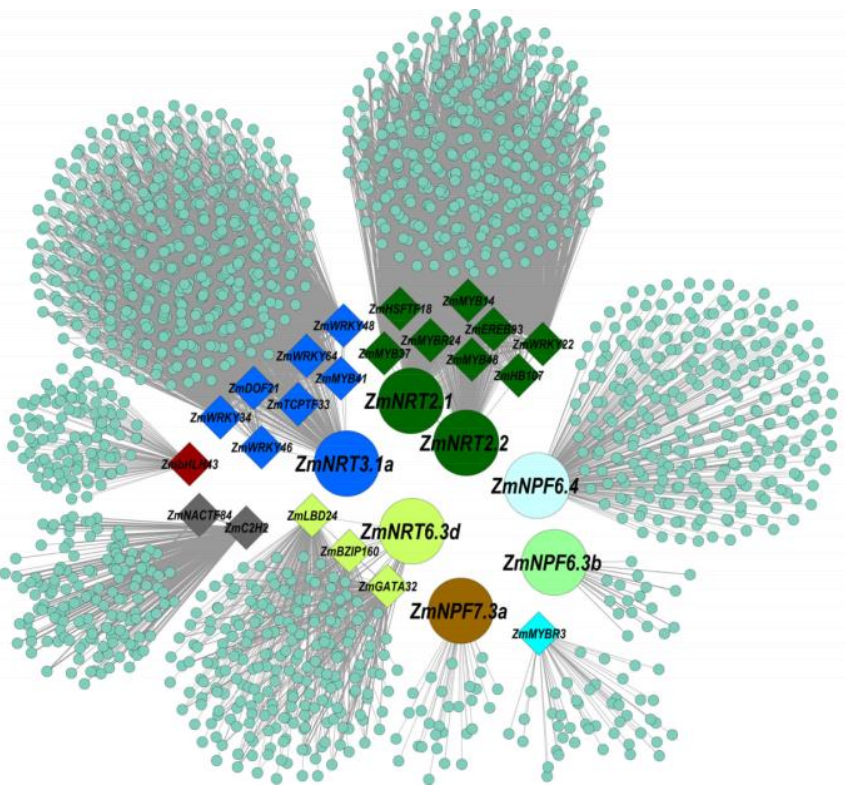

Figure 8. GAs regulated the expression of transcription factors in maize responded to $\mathrm{NO}_{3}{ }^{-}$supply. (a) Heatmap showing the significant expression of transcription factors in the 2-kb putative promoter region of nitrate transporter genes. Different expression levels were shown as $\log _{2} \mathrm{FC}$, blue for downregulation and red for upregulation, as shown in the color bar. (b) Weighted gene co-expression network analysis (WGCNA) of DEGs.

In order to investigate the potential correlations between the DEGs, a weighted-genes co-expression network analysis (WGCNA) was performed with the 3054 DEGs. As shown in Figure 8b, the genes related to nitrate transport were clustered along with the TFs displaying a predicted potential interaction into different colored modules; the genes with the same color suggest a strong co-expression relationship. For instance, ZmNRT2.1 and ZmNRT2.2 strongly co-expressed with ZmMYB14/24/37/48, ZmEREB93, ZmWRKY22, ZmHSF18, and ZmHB107. Thereafter, ZmTCP33, ZmLBD24, ZmbZIP160, ZmWRKY34, $Z m E R F 98$, and $Z m M Y B 41$ were selected for the RT-qPCR assay. The expression patterns of these genes showed a similar trend with the RNA-seq data. On the contrary, the expression levels of these TFs showed a downregulated trend in the zmga3ox plants under the LN and SN conditions, except for ZmbZIP160, which showed a marked upregulation (Figure 9). These results suggest that the GA-mediated N-uptake could occur by the transcriptional regulation of the expression of the ZmNRTs. 
(a)

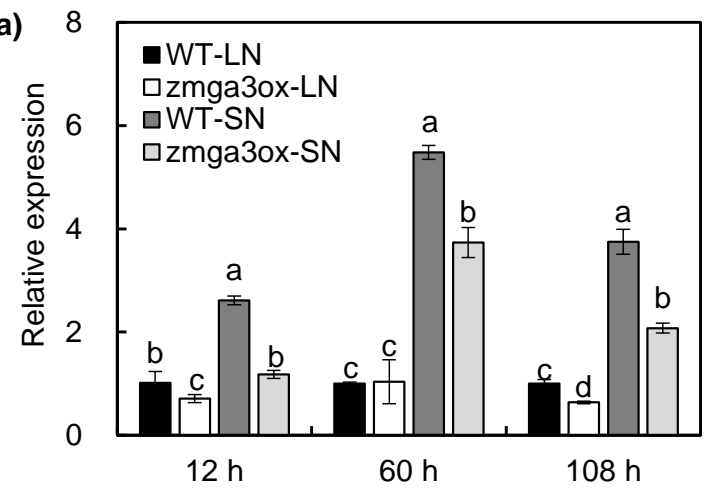

(c)

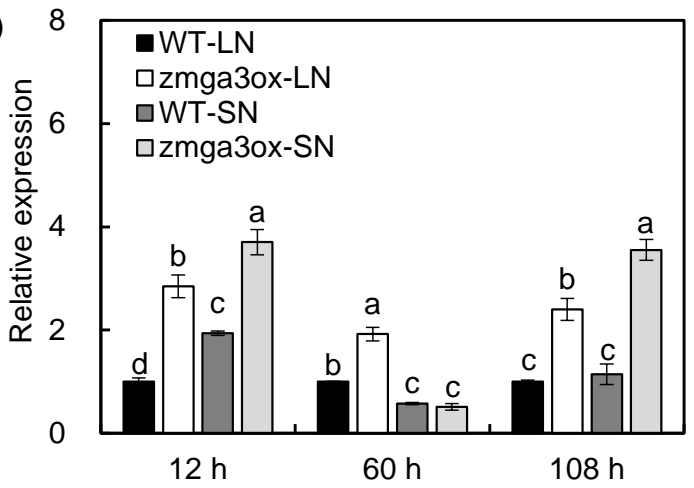

(e)

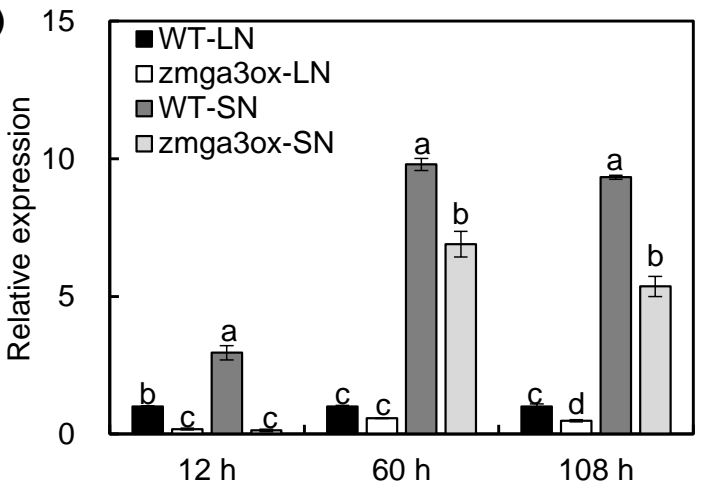

(b)

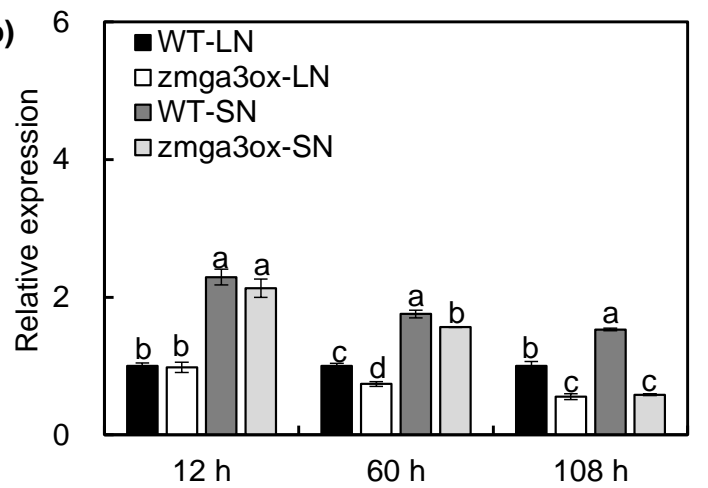

(d)

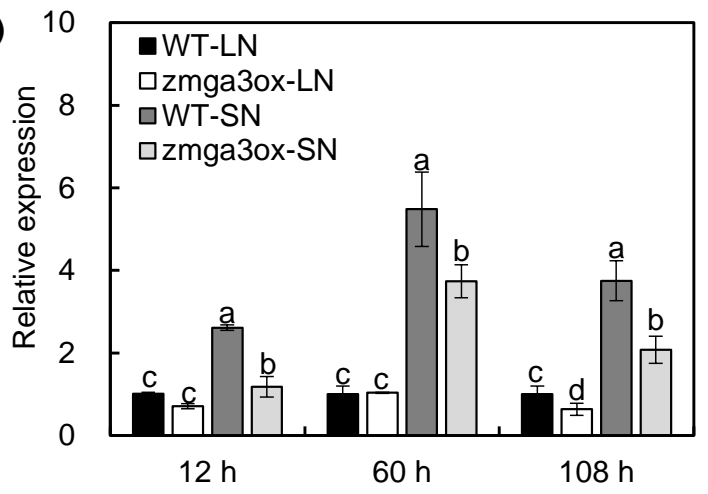

(f)

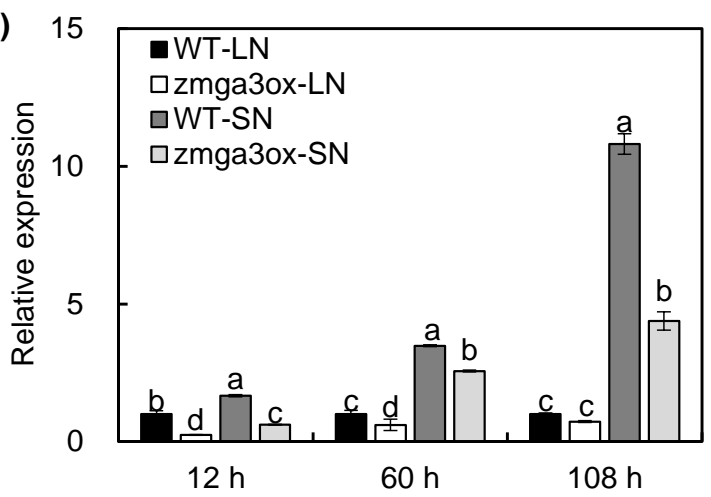

Figure 9. The expression levels of ZmTCP33 (a), ZmLBD24 (b), ZmBbZIP160 (c), ZmWRKY34 (d), ZmEREB93 (e), and ZmMYB41 (f) in wild-type and zmga3ox roots under LN and SN conditions. Roots were harvested at 12,60 , and $108 \mathrm{~h}$ after LN and SN treatments. Values were the means $\pm \mathrm{SD}(n=3)$. Different letters indicated significant difference between the wild-type and zmga3ox plants at the same time point calculated by Fisher's LSD $(p<0.05)$.

\section{Discussion}

The manipulation of the GA biosynthetic and signaling genes can modulate the plant stature and lead to a "green revolution" in the cereal crops [7,8]. However, the dwarfism contributed by the GA-related mutants occurs a lower NUE in rice and wheat production [6,18]. Actually, the mutant $s d 1$ rice plants show a lower $\mathrm{NH}_{4}{ }^{+}$uptake rate than the wild-type plants, and a lower ${ }^{15} \mathrm{NO}_{3}{ }^{-}$ uptake is also observed in the mutant Rht-B1b wheat plants [10]. In the present study, a mutant maize zmga3ox was constructed and these plants showed the dwarfed phenotype, while the addition of exogenous $\mathrm{GA}_{3}$ could restore normal growth (Figure 1). Moreover, the mutant zmga3ox plants presented significantly lower $\mathrm{NO}_{3}{ }^{-}$fluxes and ${ }^{15} \mathrm{NO}_{3}{ }^{-}$uptake, which could be restored by exogenous $\mathrm{GA}_{3}$ (Figure 4). These results suggest that the $\mathrm{N}$ uptake was decreased by the GA deficiency in maize plant, and GA accumulation might affect the maize plant for the adaptation to the $\mathrm{N}$ supply in the soil. Although the zmga3ox plants had less dry weight of shoots and roots than the wild-type plants, 
GA deficiency could not change the inhibition rate of LN to SN in the plant growth compared to the wild-type plants (Figure S4a-d). However, the inhibition rate of LN to SN in the N content was significantly modulated by GA deficiency (Figure S4e-h). These indicate that GA deficiency could not change the effects of $\mathrm{NO}_{3}{ }^{-}$-mediated plant growth, while it might have a significant effect on $\mathrm{N}$ uptake in maize exposed to LN or SN conditions.

Anthocyanin accumulation is a typical characteristic of $\mathrm{N}$ starvation, and GAs regulate the $\mathrm{N}$ deficiency-induced anthocyanin accumulation in Arabidopsis or tomato [11,12,14]. Meanwhile, low anthocyanin content in leaves is observed under normal $\mathrm{N}$ or Pi condition, and $\mathrm{GA}_{3}$ application exhibits little effects on anthocyanin accumulation. Similar results were observed in this study, where LN significantly induced anthocyanin accumulation in the zmga3ox plants, and this phenomenon could be weakened by $\mathrm{GA}_{3}$ treatment (Figure 2). Furthermore, GA deficiency had a slight effect on anthocyanin accumulation under $\mathrm{SN}$ condition. These results suggest that GA signals are involved in altering the LN-induced anthocyanin accumulation in maize. Meanwhile, the zmga3ox leaves showed higher the photosynthetic rate and chlorophyll concentration than the wild-type leaves (Figure 2c and Figure S2a); however, the leaf areas of the zmga3ox plant were significantly less than those of the wild-type plant (Figure S2b), which mainly caused low plant growth in the zmga3ox plant (Figure S4a). Contrary to the anthocyanin accumulation, LN significantly decreased the chlorophyll content and $\mathrm{N}$ content in the zmga3ox plants. Thus, the zmga3ox plants presented a significant difference in $\mathrm{N}$ content compared to the wild-type plants (Figure S4). Combined with these results, it was possible that $\mathrm{NO}_{3}{ }^{-}$ supply modulated the $\mathrm{N}$ accumulation for affecting the anthocyanin accumulation and chlorophyll content in the zmga3ox leaves. In addition, the anthocyanin accumulation is closely associated with the activities of the antioxidant enzyme system in tobacco [31], and higher anthocyanin concentration can decrease ROS accumulation in potato leaves [32]. Here, the $\mathrm{O}_{2}{ }^{-}$content in zmga3ox leaves slightly lower than that in wild-type leaves, while it showed a little higher than the anthocyanin content under SN condition (Figure S2c), which suggests that the anthocyanin accumulation might be involved in affecting the ROS accumulation in zmga3ox leaves. Further studies could research whether anthocyanin accumulation is involved in altering photosynthesis and ROS balance in zmga3ox leaves.

The $\mathrm{NO}_{3}{ }^{-}$is the main form of available inorganic $\mathrm{N}$ that is utilized by most plants from the aerobic soils, taken up by the roots and transported to the shoots before assimilation; this process is mediated by the $\mathrm{NO}_{3}{ }^{-}$transporters [19]. To date, many NPF/NRT families in Arabidopsis and rice have been functionally identified for their involvement in the root $\mathrm{NO}_{3}{ }^{-}$uptake [33]. Moreover, the expression of AtNPF6.3 and AtNRT2.1 is regulated by auxin, ethylene, and cytokinin in plants in response to $\mathrm{N}$ supply [27]. However, the process by which the GAs regulate the expression of NRTs in plants combined with sufficient or insufficient $\mathrm{N}$ is still unclear. In maize, only ZmNPF6.3a and ZmNPF6.3b genes have been cloned, $Z m N P F 6.3 b$ is a dual-affinity nitrate transporter, while ZmNPF6.3a displays a low-affinity nitrate transport activity [34]. In the present study, the expression of $Z m N P F 6.3 a$ was not significantly different in the wild-type and zmga3ox roots. Correspondingly, $\mathrm{GA}_{3}$ treatment could not alter the expression levels of ZmNPF6.3a and ZmNPF6.3b in wild-type and zmga3ox plants (Figure 5). These indicate that GAs might have a little effect on the transcriptional regulation of ZmNPF6.3a and $Z m N P F 6.3 b$ in maize responding to $\mathrm{NO}_{3}{ }^{-}$supply. Several studies have demonstrated that the ZmNRT6.3a and OsNRT1.1 $a$ display $\mathrm{NO}_{3}{ }^{-}$transport activity in maize and rice, and overexpression of OsNRT1.1 $a$ in rice greatly improved N uptake, but the expression levels of ZmNRT6.3a and OsNRT1.1a are not regulated by $\mathrm{N}$ supply [34,35]. Meanwhile, the post-translational modifications of NRT1s, such as phosphorylation and ubiquitination, are also essential for $\mathrm{NO}_{3}{ }^{-}$uptake or transport [36,37]. Here, the expression levels of ZmNPF6.3a and ZmNPF6.3b in the zmga3ox plant had no significant difference with those of the wild-type plants under SN condition (Figure $5 \mathrm{c}, \mathrm{d}$ ), but the zmga3ox plant had lower the $\mathrm{N}$ content compared to the wild-type plants (Figure 4c). These indicate whether GA could be involved in regulating the post-translational modifications of ZmNRT6.3s for altering the LATS-mediated $\mathrm{NO}_{3}{ }^{-}$uptake, which would be further studied. 
The NRT2.1 is the major HATS-type gene involved in the root $\mathrm{NO}_{3}{ }^{-}$uptake in Arabidopsis $[25,26]$. The AtNRT2.1/NRT2.2 double-knockout mutations result in up to $80 \%$ loss of the $\mathrm{NO}_{3}{ }^{-}$-inducible HATS (iHATS) activity and show severe growth restriction in the absence of the sole $\mathrm{NO}_{3}{ }^{-}$source [38]. Both the constitutive HATS (cHATS) and iHATS activities were impaired under the LN condition in the knock-outs of NRT2.1 in cucumber [39]. In the present study, the zmga3ox roots showed lower expression levels of ZmNRT2.1 and ZmNRT2.2, and this phenomenon was also found by RNA-seq analysis, while the exogenous $\mathrm{GA}_{3}$ could upregulate the expression of these genes. Moreover, the $z m g a 3 o x$ roots had lower expression levels of $Z m N R T 3.1 a$ and $Z m N R T 3.1 b$, and the functionality of NRT2.1 relies on its interacting protein NRT3.1/NAR2.1, as observed in the studies on the rice plant [40]. Thus, the $\mathrm{NO}_{3}{ }^{-}$fluxes and ${ }^{15} \mathrm{NO}_{3}{ }^{-}$uptake in zmga3ox plants were lower than those in the wild-type plants, and the $\mathrm{GA}_{3}$ treatment could increase the amount of ${ }^{15} \mathrm{~N}$. Together, GA deficiency affected $\mathrm{N}$ uptake involved in the transcriptional regulation of ZmNRT2s in the maize plant subjected to $\mathrm{NO}_{3}{ }^{-}$supply.

According to Garnett et al., the transcript abundance of putative ZmNRT2.1 and ZmNRT2.2 is correlated with the root $\mathrm{NO}_{3}{ }^{-}$uptake capacity in maize [41]. A similar result was also observed in the rice plant wherein the expression abundance of OsNRT2.3a and OsNPF2.4 was significantly decreased in the $s d 1$ mutant plant under normal $\mathrm{N}$ condition [10]. However, high $\mathrm{NO}_{3}{ }^{-}$supply increases the NRT2 transcript levels in Glycine max plants, although HATS-mediated $\mathrm{NO}_{3}{ }^{-}$influx presents a low level [42]. Similarly, the HvNRT2 transcript is upregulated by $20 \%$ to $30 \%$ in the barley plants exposed to $10 \mathrm{mM} \mathrm{NO}_{3}{ }^{-}$with tungstate (an inhibitor of nitrate reductase), while the $\mathrm{NO}_{3}{ }^{-}$influx is decreased by $50 \%$ [43]. In addition, the phosphorylation is crucial for NRT2 expression abundance in response to $\mathrm{NO}_{3}{ }^{-}$supply $[44,45]$. These indicate that the post-transcriptional modifications on iHATS-mediated $\mathrm{NO}_{3}{ }^{-}$might be exerted in the plants exposed to $\mathrm{NO}_{3}{ }^{-}$supply. In addition, the expression level of NRTs is not only regulated by the $\mathrm{NO}_{3}{ }^{-}$but also by the $\mathrm{N}$ metabolites, such as $\mathrm{NH}_{4}{ }^{+}$or amino acids $[40,44,46]$. In addition to $N$ metabolites, photosynthate (e.g., sucrose) may also influence NRTs expression [47]. Here, the KEGG analysis revealed that the most significantly enriched pathway included the N-metabolism and sucrose metabolism pathways (Figure 6b). These indicate that GAs significantly affect the $\mathrm{N}$-metabolism and sucrose metabolism pathways in maize plants responded to $\mathrm{NO}_{3}{ }^{-}$supply. Together with the findings of GAs modulating the $\mathrm{NO}_{3}{ }^{-}$uptake, GAs could regulate the transcript expression of ZmNRT2.1 and ZmNRT2.2 in maize in response to $\mathrm{N}$ supply, and might also be involved in modulating the iHATS-mediated $\mathrm{NO}_{3}{ }^{-}$uptake, which will be further investigated.

The GAs also positively regulate other nutrient-acquisition related genes, such as the Pi transporter genes SIPT2 and SIPT7 [12], the K transporter gene AtHAK5 [13], and the iron-uptake regulated genes AtIRT1 (iron-regulated transporter) and AtFRO2 (iron-regulated ferric chelate reductase) [48]. Moreover, the DELLA proteins interact with the transcription factor AtFIT and AtbHLH38/39 for modulating FIT-regulated iron-uptake regulated genes [48]. Furthermore, the transcription factor OsGRF4 drives the expression of OsNRT2.3 and OsGS1.2 in spite of being suppressed by the DELLA protein SLR1 in rice [10]. In the present study, the RNA-seq analysis revealed the presence of 287 TF genes responding to GA in the maize roots under the LN and SN conditions (Table S6). Both the binding-site prediction and co-expression analyses suggested that the ERF, MYB, WRKY, TCP, bZIP, LBD, Dof, HsF, HB, and GAGT family TFs might govern the expression of nitrate transporter genes (Figure 8). In Arabidopsis, several TFs governing the NRT2.1 and NRT1.1 expression have been identified, including the transcription factor LBD family genes (LBD37/38/39), NLP family genes (NLP7), TCP family genes (TCP20), SBP-box family genes (SPL9), and bZIP family genes (TGA1/4) [30]. Among these TFs, the transcript expressions of ZmTCP33 and ZmLBD24 were significantly repressed in the zmga3ox plant under the LN and SN conditions (Figure 9a,b). The DELLA proteins could interact with class I TCP factors and block the TCP function by binding to their DNA-recognition domains in Arabidopsis [49]. However, the transcript expression of ZmbZIP160 was upregulated in the zmga3ox plant (Figure 9c). More interestingly, the number of $M Y B, W R K Y$, and ERF family binding sites was enriched to the greatest extent, and the co-expression analysis indicated that ZmNRT2.1 and ZmNRT2.2 co-expressed with ZmMYB14/24/37/48, 
ZmEREB93, and ZmWRKY22. This aspect needs further exploration; therefore, subsequent research would be conducted to explore the transcriptional regulation of GAs modulating the expression of ZmNRT2.1 or ZmNRT1.1 in N uptake of maize.

\section{Materials and Methods}

\subsection{Plant Materials, Growth Conditions, and Treatment}

The CRISPR/Cas9 vector used to produce the zmga3ox (GRMZM2G036340) was obtained from the Maize Functional Genomic Project of China Agricultural University. The lines were produced in the maize (Zea mays L.) inbred line B73-329 background. For hydroponic experiments, the seeds were surface-sterilized in a $10 \%(v / v) \mathrm{H}_{2} \mathrm{O}_{2}$ solution for $20 \mathrm{~min}$ and washed 5 times with distilled water. After that, the seeds germinated on the sand in a growth chamber, at $28 / 22{ }^{\circ} \mathrm{C}$ with a $16 / 8 \mathrm{~h} \mathrm{light} / \mathrm{dark}$ cycle, relative humidity controlled to approximately $70-80 \%$. After germinated on the sand for $7 \mathrm{~d}$, the uniform seedlings with two visible leaves were transferred to a hydroponic box (12 seedlings per pot) containing $5 \mathrm{~L}$ nutrient solution after the endosperm of each seedling was removed. The seedlings were supplied with half-strength complete nutrient solution for $2 \mathrm{~d}$ and then transferred to the full-strength culture solution supplied with different $\mathrm{NO}_{3}{ }^{-}$concentrations $\left(2.0 \mathrm{mM} \mathrm{NO}_{3}{ }^{-}, \mathrm{SN}\right.$; $\left.0.05 \mathrm{mM} \mathrm{NO}_{3}{ }^{-}, \mathrm{LN}\right)$. To exclude the possibility of potassium $\left(\mathrm{K}^{+}\right)$interference, the concentrations of $\mathrm{K}^{+}$in the $\mathrm{LN}$ solution were supplemented to the same levels as those of the $\mathrm{SN}$ solution using $\mathrm{KCl}$. The complete nutrient solution for maize was modified Hoagland solution [50], consisting of $0.5 \mathrm{mM}$ $\mathrm{MgSO}_{4}, 0.1 \mathrm{mM} \mathrm{KH}_{2} \mathrm{PO}_{4}, 1 \mathrm{mM} \mathrm{CaCl}_{2}, 0.1 \mathrm{mM}$ EDTA-Fe, $2 \mathrm{mM} \mathrm{KNO}_{3}$, and micronutrients $(0.03 \mathrm{mM}$ $\mathrm{H}_{3} \mathrm{BO}_{3}, 0.0025 \mathrm{mM} \mathrm{ZnSO}_{4}, 0.008 \mathrm{mM} \mathrm{CuSO}_{4}, 0.005 \mathrm{mM} \mathrm{MnSO}_{4}$, and $0.0003 \mathrm{mM}(\mathrm{NH} 4)_{6} \mathrm{Mo}_{7} \mathrm{O}_{24}$, and $\mathrm{pH}$ 5.8. The nutrient solution was renewed every other day. In addition, the nutrient solution, with or without $1 \mu \mathrm{M} \mathrm{GA}_{3}$ or $2 \mu \mathrm{M} \mathrm{Ucz}$, was treated simultaneously with $\mathrm{LN}$ or SN treatment for $5 \mathrm{~d}$.

For soil culture experiments, the wide-type and zmga3ox seeds were sown in plastic containers $(20 \times 20 \times 30 \mathrm{~cm}$ deep) with a mixture of vermiculite and commercial garden soil $(1: 1 ; v / v)$ in a glasshouse. And $0.1 \mathrm{mM} \mathrm{GA}_{3}$ with $0.01 \%(v / v)$ Tween 20 were applied by foliar spray by using perfume bottles every other day.

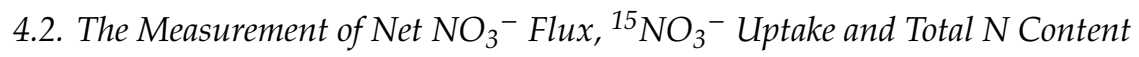

The net $\mathrm{NO}_{3}{ }^{-}$fluxes were measured in the maturation zone (approximately $700 \mu \mathrm{m}$ from the root tip) of PR using the non-invasive micro-test (NMT) system (Younger; Xuyue (Beijing) Sci \& Tech) [51]. For each experimental group, maize seedlings were selected at $5 \mathrm{~d}$ after LN or SN treatment, and the roots were immediately equilibrated in a Petri dish containing $10 \mathrm{~mL}$ of measuring solution $(0.1 \mathrm{mM}$ $\mathrm{NH}_{4} \mathrm{NO}_{3}, 0.1 \mathrm{mM} \mathrm{KCl}, 0.1 \mathrm{mM} \mathrm{CaCl} 2,0.3 \mathrm{mM}$ MES, $\mathrm{pH}$ 6.0) for $20 \mathrm{~min}$, and then transferred to another

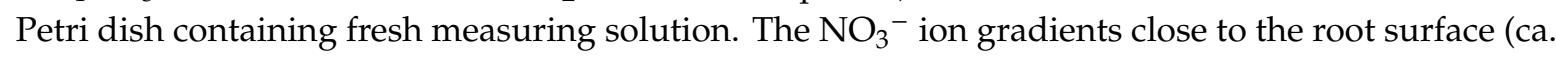
$5 \mu \mathrm{m}$ above the root surface) were determined by moving the flux microsensor between two positions (30 $\mu \mathrm{m}$ in distance) in the direction perpendicular to the root axis. The recording rate of ion flux was one reading per $6 \mathrm{~s}$, and each measurement point was monitored for $10 \mathrm{~min}$.

The $\mathrm{N}$ uptake assay in roots of the zmga3ox seedling was performed as described previously [10]. After LN or SN treatment for $5 \mathrm{~d}$, the uniform seedlings were selected and rinsed the roots with $0.1 \mathrm{mM}$ $\mathrm{CaSO}_{4}$ solution for $1 \mathrm{~min}$, and then incubated in the nutrient solution containing 0.05 or $2 \mathrm{mM} \mathrm{K}^{15} \mathrm{NO}_{3}$ with a $99 \%$ atom excess of ${ }^{15} \mathrm{~N}$, respectively, for $10 \mathrm{~min}$. After that, washed for $1 \mathrm{~min}$ in $0.1 \mathrm{mM} \mathrm{CaSO}_{4}$ solution before sampling. The samples were harvested and dried at $120^{\circ} \mathrm{C}$ for $30 \mathrm{~min}$, and then $65^{\circ} \mathrm{C}$ for $72 \mathrm{~h}$ before being ground. The power was used for total ${ }^{15} \mathrm{~N}$ determination by isotope ratio mass spectrometry (Vario PYRO cube ISOprime 100, Cheadle Hulme, UK).

The roots and shoots of maize seedlings at $5 \mathrm{~d}$ after LN or SN treatment were separated for assay of $\mathrm{N}$ concentration following the Kjeldahl method [52]. Plant total $\mathrm{N}$ content was calculated as the product of $\mathrm{N}$ concentration and corresponding dry weight. 


\subsection{RNA Isolation and Reverse Transcription Quantitative Polymerase Chain Reaction (RT-qPCR) Analysis}

Total RNA was isolated from each sample using the Plant RNeasy Mini kit (Tiangen, Beijing, China). Then the full-length cDNA was synthesized from 2 ug of RNA using Oligo d (T) primer and M-MLV reverse transcriptase (Takara, kusatsu, Japan). Quantitive PCR was conducted in an Applied Biosystems 7500 Fast Real-Time PCR System (Applied Biosystems, CA, USA) using SYBR ${ }^{\circledR}$ Premix Ex Taq ${ }^{\text {TM }}$ (Takara, Japan) following the manufacturer's instructions. ZmUBC (ubiquitin C) was used to normalize gene expression [53]. Fold change of gene expression values were calculated using the $2^{-\Delta \Delta C \mathrm{t}}$ method [54]. The primers for qRT-PCR are listed in Table S8.

\subsection{RNA-Seq Analysis}

Three biological RNA replicates were obtained from the root of wild-type and zmga30x plants at 12,60 , and $108 \mathrm{~h}$ after LN or SN treatment, each biological replicate contained roots from three plants. Library construction for transcriptome sequencing was performed using the NEBNext UltraTM RNA Library Prep Kit for Illumina (NEB, Ipswich, MA, USA). The clustering of the index-coded samples was performed on a cBot Cluster Generation System using a TruSeq PE Cluster Kit v4-cBot-HS (Illumia) according to the manufacturer's instructions. After cluster generation, the library preparations were sequenced on an Illumina Hiseq 4000 platform, and paired-end $150 \mathrm{bp}$ reads were generated. Clean data (clean reads) were obtained by removing reads with adapter reads containing ploy- $\mathrm{N}$ and low quality reads from raw data. At the same time, Q20, Q30, GC-content, and sequence duplication levels of the clean data were calculated. All the downstream analyses were based on clean data with high quality. The filtered reads from each sample were aligned to the maize reference genome (B73 RefGen_v3, http://www.maizegdb.org/assembly/) using TopHat2 [55]. Gene expression levels were estimated by fragments per kilobase of transcript per million reads (FPKM) to compare among different samples. EdgeR software package [56] was used to detect genes differentially expressed between wild-type and zmga3ox mutant. K-means clustering analysis was conducted by cluster 3.0 between LN and SN at three time points and visualized by using Java TreeView. A gene was regarded as significantly differentially expressed if the false discovery rate (FDR) adjusted to a $p$-value $<0.05$ and $\log _{2}$ (fold change) $\geq 1$.

Gene Ontology (GO) and Kyoto Encyclopedia of Genes and Genomes (KEGG) pathway annotation and enrichment analyses of DEGs were performed by the online agriGO software [57] and KOBAS 3.0 software [58], respectively.

\subsection{Weighted Gene co-Expression Network Analysis (WGCNA)}

The FPKM of DEGs was adopted to process the raw files as the input file for WGCNA. The expression data from all three time points were analyzed combined. The co-expression networks were constructed with R package WGCNA (version 1.66) [59]. The soft thresholding power was 14, minModuleSize was 20, deepSplit was 2, networkType was signed, and others were default settings following previous descriptions [60]. The co-expression network was visualized with Cytoscape 3.7.1 [61].

\subsection{Transcription Factor-binding Site Prediction}

Putative promoter sequences ( $2 \mathrm{~kb}$ upstream from the transcriptional start site) of DEGS were downloaded from Ensemble Plants (http://plants.ensembl.org). Then the TF-binding site prediction was performed with online software PlantRegMap (http://plantregmap.cbi.pku.edu.cn), according to Jin et al. [62].

\subsection{GAs Concentration Analysis}

The roots or shoots of wild-type and zmga3ox seedlings were collected at $5 \mathrm{~d}$ after LN or $\mathrm{SN}$ treatment. The endogenous concentration of GAs was determine by HPLC-MS/MS. Briefly, 
approximately $500 \mathrm{mg}$ of tissue was ground in liquid nitrogen and then extracted with $5 \mathrm{~mL}$ of $90 \%$ aqueous $\mathrm{MeOH}$. Simultaneously, $2 \mathrm{ng}$ of each D-labeled gibberellin compound was added to each sample. The subsequent operation was performed as described by [63].

\subsection{Assay of Physiological and Biochemical Properties}

After LN treatment for $5 \mathrm{~d}, 0.2 \mathrm{~g}$ fresh leaves or roots of wild-type and zmga3ox seedlings were collected for analyzing the activities of GS and NR. Chlorophyll content was measured following Wu et al. [64]. The anthocyanin content was determined, as described previously [65]. The activities of GS and NR were determined, respectively, with the Glutamine Synthetase and Nitrate Reductase Kit (Solarbio LIFE SCIENCES, BC0910/ BC0080, Beijing, China) following the manufacturer's instructions. The $\mathrm{O}_{2}{ }^{-}$production rate was determined with the protocol described by Chen et al. [66]. The photosynthetic rate was assessed by using an LI-6400 XT portable photosynthetic system (LI-COR, Lincoln, NE, USA). Leaf area was calculated by using a Li-3000C portable leaf meter.

\subsection{Statistical Analysis}

The data were statistically analyzed using SAS 9.0 (SAS Institute Inc., Cary, NC, USA). The Student's $\mathrm{t}$-test was used for comparisons between two groups of data. For the data sets of more than two groups, one-way ANOVA with LSD $(p<0.05)$ was used.

\section{Conclusions}

Taken together, the results of the present study indicate that GA plays a significant role in the regulation of nitrogen uptake in the maize plant in response to $\mathrm{N}$ supply. LN significantly repressed the level of the bioactive GAs in the roots. Moreover, the shoots of the zmga3ox plants showed more sensitivity toward the LN stress, corresponding to the contribution of anthocyanin accumulation and the decrease of chlorophyll content. Also, the zmga3ox plants had low net $\mathrm{NO}_{3}{ }^{-}$fluxes leading to lesser ${ }^{15} \mathrm{~N}$ content compared to the wild-type plants. The transcript expression of ZmNRTs was downregulated in the zmga3ox roots under the LN and SN conditions. These results suggested that GAs regulated N uptake involved in transcriptional regulation of NRTs expression and the physiological responses in maize responding to nitrogen availability. This research thus provides a valuable theoretical basis for improving $\mathrm{N}$ efficiency in crop production.

Supplementary Materials: Supplementary materials can be found at http://www.mdpi.com/1422-0067/21/5/1824/s1.

Author Contributions: M.Z., G.M., and Z.L. designed and conceived the experiments. Y.W. performed most of the experiments with the help from Y.Z. (Yushi Zhang), Y.Z. (Yuexia Zhang), J.X., B.Y.; Q.Y. performed the RNA-seq analysis; M.Z. supervised the project; Y.W. and M.Z. wrote the paper. All authors have read and agreed to the published version of the manuscript.

Funding: This work was supported by the National Nature Science Foundation of China (Grant No. 31425017) and the National Key Research and Development Program of China (Grant No. 2017YFD0300410).

Acknowledgments: The maize seeds were produced by the Maize Functional Genomic Platform of China Agricultura University.

Conflicts of Interest: The authors have declared no conflict of interests. The funders had no role in the design of the study; in the collection, analyses, or interpretation of data; in the writing of the manuscript, or in the decision to publish the results. 


\section{Abbreviations}

$\begin{array}{ll}\text { GA } & \text { Gibberellin } \\ \text { GS } & \text { Glutamine Synthase } \\ \text { NR } & \text { Nitrate Reductase } \\ \text { LN } & \text { Low Nitrate } \\ \text { NUE } & \text { Nitrogen Use Efficiency } \\ \text { NMT } & \text { Non-Invasive Micro-Test System } \\ \text { NRT } & \text { Nitrate Transport } \\ \text { PR } & \text { Primary Root } \\ \text { SN } & \text { Sufficient Nitrate } \\ \text { Ucz } & \text { Uniconazole } \\ \text { FPKM } & \text { Fragments per Kilobase of Transcript per Million Reads } \\ \text { FDR } & \text { False Discovery Rate } \\ \text { DEGs } & \text { Differentially Expressed Genes } \\ \text { NRT } & \text { Nitrate Transporter } \\ \text { GRF4 } & \text { Growth-Regulattion Factor 4 } \\ \text { HAK5 } & \text { High-Affinity Potassium Transporter 5; } \\ \text { SLR1 } & \text { Slender Rice1 } \\ \text { SIPT2 } & \text { Tomato Phosphate Transporter } \\ \text { IRT1 } & \text { Iron-Regulated Transporter 1 } \\ \text { FRO2 } & \text { Iron Regulated Ferric Chelate Reductase } \\ \text { WGCNA } & \text { Weighted Gene co-Expression Network Analysis } \\ \text { GO } & \text { Gene Ontology } \\ \text { KEGG } & \text { Kyoto Encyclopedia of Genes and Genomes } \\ \text { NPF } & \text { Nitrate Transporter1/Peptide Transporter Family } \\ \end{array}$

\section{References}

1. Yamaguchi, S. Gibberellin metabolism and its regulation. J. Plant Growth Regul. 2008, 59, 225-251. [CrossRef] [PubMed]

2. Colebrook, E.H.; Thomas, S.G.; Phillips, A.L.; Hedden, P. The role of gibberellin signalling in plant responses to abiotic stress. J. Exp. Biol. 2014, 217, 67-75. [CrossRef] [PubMed]

3. Chen, Y.; Hou, M.M.; Liu, L.J.; Wu, S.; Shen, Y.; Ishiyama, K.; Kobayashi, M.; McCarty, D.R.; Tan, B.-C. The maize DWARF1 encodes a Gibberellin 3-Oxidase and is dual localized to the nucleus and cytosol. Plant Physiol. 2014, 166, 2028-2039. [CrossRef] [PubMed]

4. Plackett, A.R.; Powers, S.J.; Fernandez-Garcia, N.; Urbanova, T.; Takebayashi, Y.; Seo, M.; Jikumaru, Y.; Benlloch, R.; Nilsson, O.; Ruiz-Rivero, O.; et al. Analysis of the developmental roles of the Arabidopsis gibberellin 20-oxidases demonstrates that GA20ox1, -2, and-3 are the dominant paralogs. Plant Cell 2012, 24, 941-960. [CrossRef] [PubMed]

5. Harberd, N.P.; Belfield, E.; Yasumura, Y.K. The angiosperm Gibberellin-GID1-DELLA growth regulatory mechanism: How an "inhibitor of an inhibitor" enables flexible response to fluctuating environments. Plant Cell 2009, 21, 1328-1339. [CrossRef] [PubMed]

6. Hedden, P. Constructing dwarf rice. Nat. Biotechnol. 2003, 21, 873-874. [CrossRef]

7. Peng, J.R.; Richards, D.E.; Hartley, N.M.; Murphy, G.P.; Devos, K.M.; Flintham, J.E.; Beales, J.; Fish, L.J.; Worland, A.J.; Harberd, N.P. 'Green revolution' genes encode mutant gibberellin response modulators. Nature 1999, 400, 256-261. [CrossRef]

8. Itoh, H.; Ueguchi-tanaka, M.; Sato, Y.; Ashikari, M.; Matsuoka, M. The gibberellin signaling pathway is regulated by the appearance and disappearance of SLENDER RICE1 in nuclei. Plant Cell 2002, 14, 57-70. [CrossRef]

9. Asano, K.; Yamasaki, M.; Takuno, S.; Miura, K.; Katagiri, S.; Tomoko, I.; Doi, K.; Wu, J.; Ebana, K.; Matsumoto, T.; et al. Artificial selection for a green revolution gene during japonica rice domestication. Proc. Natl. Acad. Sci. USA 2011, 108, 11034-11039. [CrossRef] 
10. Li, S.; Tian, Y.H.; Wu, K.; Ye, Y.F.; Yu, J.P.; Zhang, J.; Liu, Q.; Hu, M.; Li, H.; Tong, Y.; et al. Modulating plant growth-metabolism coordination for sustainable agriculture. Nature 2018, 560, 595-600. [CrossRef]

11. Jiang, C.F.; Gao, X.H.; Liao, L.L.; Harberd, N.P.; Fu, X.D. Phosphate starvation root architecture and anthocyanin accumulation responses are modulated by the Gibberellin-DELLA signaling pathway in Arabidopsis. Plant Physiol. 2007, 145, 1460-1470. [CrossRef]

12. Zhang, Y.Q.; Zhou, Y.W.; Chen, S.Y.; Liu, J.L.; Fan, K.; Li, Z.W. Gibberellins play dual roles in response to phosphate starvation of tomato seedlings, negatively in shoots but positively in roots. J. Plant Physiol. 2019, 234, 145-153. [CrossRef]

13. Oliferuk, S.; Pérez, A.; Martinez, V.; Ródenas, R.; Ribio, F.; María, G.E.S. How DELLAs contribute to control potassium uptake under conditions of potassium scarcity? hypotheses and uncertainties. Plant Signal. Behav. 2017, 12, 1559-2324. [CrossRef]

14. Zhang, Y.Q.; Liu, Z.J.; Liu, J.P.; Liu, S.; Wang, J.F.; Liu, W.X.; Xu, W.F. GA-DELLA pathway is involved in regulation of nitrogen deficiency-induced anthocyanin accumulation. Plant Cell Rep. 2017, 36, 557-569. [CrossRef]

15. Khan, N.A. Effect of gibberellic acid on carbonic anhydrase, photosynthesis, growth and yield of mustard. Biol. Plant. 1996, 38, 145-147. [CrossRef]

16. Nagel, O.W.; Lambers, H. Changes in the acquisition and partitioning of carbon and nitrogen in the gibberellin-deficient mutants A70 and W335 of tomato (Solanum lycopersicum L.). Plant Cell Environ. 2002, 25, 883-891. [CrossRef]

17. Bai, L.Q.; Deng, H.Q.; Zhang, X.C.; Yu, X.C.; Li, Y.S. Gibberellin is involved in inhibition of cucumber growth and nitrogen uptake at suboptimal root-zone temperatures. PLoS ONE 2016, 11, e0156188. [CrossRef]

18. Gooding, M.J.; Addisu, M.; Uppal, R.K.; Snape, J.W.; Jones, H.E. Effect of wheat dwarfing genes on nitrogen-use efficiency. J. Agric. Sci. 2012, 150, 3-22. [CrossRef]

19. Xu, G.H.; Fan, X.R.; Miller, A.J. Plant nitrogen assimilation and use efficiency. Annu. Rev. Plant Biol. 2012, 63, 153-182. [CrossRef]

20. Pingali, P.L. Green Revolution: Impacts, limits, and the path ahead. Proc. Natl. Acad. Sci. USA 2012, 109, 12302-12308. [CrossRef]

21. Rogers, E.D.; Benfey, P.N. Regulation of plant root system architecture: Implications for crop advancement. Curr. Opin. Biotechnol. 2015, 32, 93-98. [CrossRef] [PubMed]

22. Lassaletta, L.; Billen, G.; Grizzetti, B.; Anglade, J.; Garnier, J. 50 year trends in nitrogen use efficiency of world cropping systems: The relationship between yield and nitrogen input to cropland. Environ. Res. Lett. 2014, 9 , 105011. [CrossRef]

23. Hirel, B.; Gouis, J.L.; Ney, B.; Gallais, A. The challenge of improving nitrogen use efficiency in crop plants: Towards a more central role for genetic variability and quantitative genetics within integrated approaches. J. Exp. Bot. 2007, 58, 2369-2387. [CrossRef] [PubMed]

24. Foyer, C.H.; Valadier, M.H.; Migge, A.; Becker, T.W. Drought-induced effects on nitrate reductase activity and mRNA and on the coordination of nitrogen and carbon metabolism in maize leaves. Plant Physiol. 1998, 1, 283-292. [CrossRef] [PubMed]

25. Tsay, Y.F.; Chiu, C.C.; Tsai, C.B.; Ho, C.H.; Hsu, P.K. Nitrate transporters and peptide transporters. FEBS Lett. 2007, 581, 2290-2300. [CrossRef] [PubMed]

26. Leran, S.; Varala, K.; Boyer, J.C.; Chiurazzi, M.; Crawford, N.; Daniel-Vedele, F.; David, L.; Dickstein, R.; Fernandez, E.; Forde, B.; et al. A unified nomenclature of NITRATE TRANSPORTER 1/PEPTIDE TRANSPORTER family members in plants. Trends Plant Sci. 2014, 19, 1360-1385. [CrossRef]

27. Kiba, T.; Kudo, T.; Kojima, M.; Sakakibara, H. Hormonal control of nitrogen acquisition: Roles of auxin, abscisic acid, and cytokinin. J. Exp. Bot. 2011, 62, 1399-1409. [CrossRef]

28. Mu, X.H.; Chen, Q.W.; Wu, X.Y.; Chen, F.J.; Yuan, L.X.; Mi, G.H. Gibberellins synthesis is involved in the reduction of cell flux and elemental growth rate in maize leaf under low nitrogen supply. Environ. Exp. Bot. 2018, 150, 198-208. [CrossRef]

29. Xing, H.L.; Dong, L.; Wang, Z.P.; Zhang, H.Y.; Han, C.Y.; Liu, B.; Wang, X.C.; Chen, Q.J. A CRISPR/Cas9 toolkit for multiplex genome editing in plants. BMC Plant Biol. 2014, 14, 327. [CrossRef]

30. Zhao, L.F.; Liu, F.; Crawford, N.M.; Yong, W. Molecular regulation of nitrate response in plants. Int. J. Mol. Sci. 2018, 19, 2039. [CrossRef] 
31. Naing, A.H.; Park, K.I.; Ai, T.N.; Chung, M.Y.; Han, J.S.; Kang, Y.W.; Lim, K.B.; Kim, C.K. Overexpression of snapdragon Delila (Del) gene in tobacco enhances anthocyanin accumulation and abiotic stress tolerance. BMC Plant Biol. 2017, 17, 65. [CrossRef] [PubMed]

32. Cheng, Y.J.; Kim, M.D.; Deng, X.P.; Kwak, S.S.; Chen, W. Enhanced salt stress tolerance in transgenic potato plants expressing IbMYB1, a sweet potato transcription factor. J. Microbiol. Biotechnol. 2013, 23, 1737-1746. [CrossRef] [PubMed]

33. Xuan, W.; Beeckman, T.; Xu, G.H. Plant nitrogen nutrition: Sensing and signaling. Curr. Biol. Plant Biol. 2017, 39, 57-65. [CrossRef] [PubMed]

34. Wen, Z.; Tyerman, S.D.; Dechorgnat, J.; Ovchinnikova, E.; Dhugga, K.S.; Kaiser, B.N. Maize NPF6 proteins are homologs of Arabidopsis CHL1 that are selective for both nitrate and chloride. Plant Cell 2017, 29, 2581-2596. [CrossRef] [PubMed]

35. Wang, W.; Hu, D.; Yuan, D.Y.; Liu, Y.Q.; Che, R.H.; Hu, Y.Q.; Ou, S.; Liu, Y.; Zhang, Z.; Wang, H.; et al. Expression of the nitrate transporter gene OsNRT1.1A/OsNPF6.3 confers high yield and early maturation in rice. Plant Cell 2018, 30, 638-651. [CrossRef]

36. Ho, C.H.; Lin, S.H.; Hu, H.C.; Tsay, Y.F. CHL1 functions as a nitrate sensor in plants. Cell 2009, 138, 1184-1194. [CrossRef]

37. Liu, W.; Sun, Q.; Wang, K.; Du, Q.; Li, W.X. Nitrogen Limitation Adaptation (NLA) is involved in source-to-sink remobilization of nitrate by mediating the degradation of NRT1.7 in Arabidopsis. New Physiol. 2017, 214, 734-744. [CrossRef]

38. Li, W.; Wang, Y.; Okamoto, M.; Crawford, N.M.; Siddiqi, M.Y.; Glass, A.D. Dissection of the AtNRT2.1:AtNRT2.2 inducible high-affinity nitrate transporter gene cluster. Plant Physiol. 2007, 143, 425-433. [CrossRef]

39. Li, Y.; Li, J.Q.; Yan, Y.; Liu, W.Q.; Zhang, W.N.; Guo, L.H.; Tian, Y.Q. Knock-Down of CsNRT2.1, a Cucumber Nitrate Transporter, Reduces Nitrate Uptake, Root length, and Lateral Root Number at Low External Nitrate Concentration. Front. Plant Sci. 2018, 9, 722. [CrossRef]

40. Yan, M.; Fan, X.; Feng, H.M.; Miller, A.J.; Shen, Q.R.; Xu, G.H. Rice OsNAR2.1 interacts with OsNRT2.1, OsNRT2.2 and OsNRT2.3a nitrate transporters to provide uptake over high and low concentration ranges. Plant Cell Environ. 2011, 34, 1360-1372. [CrossRef]

41. Garnett, T.; Conn, V.; Plett, D.; Conn, S.; Zanghellini, J.; Mackenzie, N.; Enju, A.; Francis, K.; Holtham, L.; Roessner, U.; et al. The response of the maize nitrate transport system to nitrogen demand and supply across the lifecycle. New Phytol. 2013, 198, 82-94. [CrossRef] [PubMed]

42. Amarasinghe, B.H.R.; de Bruxelles, G.L.; Braddon, M.; Onyeocha, I.; Forde, B.G.; Udvardi, M.K. Regulation of GmNRT2 expression and nitrate transport activity in roots of soybean (Glycine max). Planta 1998, 206, 44-52. [CrossRef] [PubMed]

43. Vidmar, J.J.; Zhuo, D.; Siddiqi, M.Y.; Schjoerring, J.K.; Touraine, B.; Glass, A.D. Regulation of high-affinity nitrate transporter genes and high-affinity nitrate influx by nitrogen pools in roots of barley. Plant Physiol. 2000, 123, 307-318. [CrossRef] [PubMed]

44. Orsel, M.; Filleur, S.; Fraisier, V.; Daniel-Vedele, F.D. Nitrate transport in plants: Which gene and which control? J. Exp. Bot. 2002, 53, 825-833. [CrossRef] [PubMed]

45. Zhou, X.; Liu, M.Y.; Wu, W.H.; Wang, Y. Phosphorylation at Ser28 stabilizes the Arabidopsis nitrate transporter NRT2.1 in response to nitrate limitation. J. Integr. Plant Biol. 2019. [CrossRef] [PubMed]

46. Zhuo, D.G.; Okamoto, M.; Vidmar, J.J.; Glass, A.D.M. Regulation of a putative high-affinity nitrate transporter (Nrt2;1At) in roots of Arabidopsis thaliana. Plant J. 1999, 17, 563-568. [CrossRef]

47. Lejay, L.; Gansel, X.; Cerezo, M.; Tillard, P.; Muller, C.; Krapp, A.; von Wiren, N.; Daniel-Vedele, F.; Gojon, A. Regulation of root ion transporters by photosynthesis: Functional importance and relation with hexokinase. Plant Cell 2003, 15, 2218-2232. [CrossRef]

48. Wild, M.; Davie, J.M.; Regnault, T.; Sakvarelidze-Achard, L.; Carrera, E.; Diaz, I.L.; Cayrel, A.; Dubeaux, G.; Vert, G.; Vert, G.; et al. Tissue-specific regulation of gibberellin signaling article tissue-specific regulation of gibberellin signaling fine-tunes Arabidopsis iron-deficiency responses. Dev. Cell 2016, 37, 190-200. [CrossRef]

49. Daviere, J.M.; Wild, M.; Regnault, T.; Baumberger, N.; Eisler, H.; Genschik, P.; Achard, P. Report class I TCP-DELLA interactions in inflorescence shoot apex determine plant height. Curr. Biol. 2014, 24, 1923-1928. [CrossRef] 
50. Mengel, K.; Robin, P.; Salsac, L. Nitrate reductase activity in shoots and roots of maize seedlings as affected by the form of nitrogen nutrition and the $\mathrm{pH}$ of the nutrient solution. Plant Physiol. 1983, 71, 618-622. [CrossRef]

51. Luo, J.; Qin, J.J.; He, F.F.; Li, H.; Liu, T.X.; Polle, A.; Peng, C.H.; Luo, Z.B. Net fluxes of ammonium and nitrate in association with $\mathrm{H}^{+}$fluxes in fine roots of Populus popularis. Planta 2013, 237, 919-931. [CrossRef] [PubMed]

52. Li, B.Z.; Xin, W.J.; Sun, S.B. Physiological and molecular responses of nitrogen-starved rice plants to re-supply of different nitrogen sources. Plant Soil 2006, 287, 145-159. [CrossRef]

53. Gao, Y.Q.; Wu, W.H.; Wang, Y. The $\mathrm{K}^{+}$channel KZM2 is involved in stomatal movement by modulating inward $\mathrm{K}^{+}$currents in maize guard cells. Plant J. 2017, 92, 662-675. [CrossRef] [PubMed]

54. Livak, K.J.; Schmittgen, T.D. Analysis of relative gene expression data using real-time quantitative PCR and the $2^{-\Delta \Delta C}$ T method. Methods 2001, 25, 402-408. [CrossRef]

55. Kim, D.; Pertea, C.; Trapnell, C. TopHat2 accurate alignment of transcriptomes in the presence of insertions, deletions and gene fusions. Genome Biol. 2013, 14, R36. [CrossRef]

56. Robinson, M.D.; McCarthy, D.J.; Smyth, G.K. edgeR: A bioconductor package for differential expression analysis of digital gene expression data. Bioinformatics 2010, 26, 139-140. [CrossRef]

57. Du, Z.; Zhou, X.; Ling, Y.; Zhang, Z.H.; Su, Z. agriGO: A GO analysis toolkit for the agricultural community. Nucleic Acids Res. 2010, 38, W64-W70. [CrossRef]

58. Wu, J.M.; Mao, X.Z.; Cai, T.; Luo, J.C.; Wei, L.P. KOBAS server: A web-based platform for automated annotation and pathway identification. Nucleic Acids Res. 2006, 34, W720-W724. [CrossRef]

59. Zhang, B.; Horvath, S. A general framework for weighted gene co-expression network analysis. Genet. Mol. Biol. 2005, 4, 1544-6115. [CrossRef]

60. Langfelder, P.; Horvath, S. WGCNA: An R package for weighted correlation network analysis. BMC Bioinform. 2008, 9, 559. [CrossRef]

61. Saito, R.; Smoot, M.E.; Ono, K.; Ruscheinski, J.; Wang, P.L.; Lotia, S.; Pico, A.R.; Bader, G.D.; Ideker, T. A travel guide to Cytoscape plugins. Nat. Methods 2012, 9, 1069-1076. [CrossRef] [PubMed]

62. Jin, J.P.; Tian, F.; Yang, Y.Q.; Kong, M.L.; Luo, J.C.; Gao, G. PlantTFDB 4.0: Toward a central hub for transcription factors and regulatory interactions in plants. Nucleic Acids Res. 2017, 45, D1040-D1045. [CrossRef] [PubMed]

63. Ma, X.D.; Ma, J.; Zhai, H.H.; Xin, P.Y.; Chu, J.F.; Qiao, Y.L.; Han, L.Z. CHR729 is a CHD3 protein that controls seedling development in rice. PLoS ONE 2015, 10, e0138934. [CrossRef] [PubMed]

64. Wu, X.Y.; Ding, C.H.; Baerson, S.R.; Lian, F.H.; Lin, X.H.; Zhang, L.Q.; Wu, C.F.; Hwang, S.Y.; Zeng, R.S.; Song, Y.Y. The roles of jasmonate signalling in nitrogen uptake and allocation in rice (Oryza sativa L.). Plant Cell Environ. 2018, 42, 659-672. [CrossRef]

65. Vandenbussche, F.; Habricot, Y.; Condiff, A.S.; Maldiney, R.; Straeten, V.D.; Ahmad, M. HY5 is a point of convergence between cryptochrome and cytokinin signalling pathways in Arabidopsis thaliana. Plant J. 2007, 49, 428-441. [CrossRef]

66. Chen, Y.E.; Cui, J.M.; Li, G.X.; Yuan, M.; Zhang, Z.W.; Yuan, S.; Zhang, H.Y. Effect of salicylic acid on the antioxidant system and photosystem II in wheat seedlings. Biol. Plant. 2016, 60, 139-147. [CrossRef]

(C) 2020 by the authors. Licensee MDPI, Basel, Switzerland. This article is an open access article distributed under the terms and conditions of the Creative Commons Attribution (CC BY) license (http://creativecommons.org/licenses/by/4.0/). 